\title{
Hybrid Fuzzy MCDM Model for Z-numbers using Intuitive Vectorial Centroid
}

\author{
${ }^{1}$ Ku Muhammad Naim Ku Khalif, ${ }^{1}$ Alexander Gegov, ${ }^{2,3}$ Ahmad Syafadhli Abu Bakar \\ ${ }^{1}$ School of Computing, University of Portsmouth, Portsmouth PO1 3HE, United Kingdom \\ ${ }^{2}$ Department of Mathematics, Centre for Foundation Studies, University of Malaya, Malaysia. \\ ${ }^{3}$ Centre of Research for Computational Sciences \& Informatic Biology, Bioindustry, Environment, Agriculture and Healthcare \\ muhammad.khalif@port.ac.uk, alexander.gegov@port.ac.uk, ahmadsyafadhli@um.edu.my
}

\begin{abstract}
This paper presents a hybrid fuzzy multi criteria decision making model for $z$-numbers using intuitive vectorial centroid. There are two novelty discuss here: 1) development of intuitive vectorial centroid defuzzification and; 2) development of hybrid fuzzy multi criteria decision making model based on consistent fuzzy preference relations and fuzzy technique for order performance by similarity to ideal solution for z-numbers. The implementation of $z$-numbers is taken into consideration, where it has more authority to describe the knowledge of human being and extensively used in the uncertain information development to deal with linguistic decision making problems. Fuzziness is not sufficient enough when dealing with real information and a degree of reliability of the information is very critical. It also highlights the combination of z-numbers with multi criteria decision making techniques allow the use of fuzzy linguistic by considering the need of human intuition in decision making problems. The proposed methodology is applied to staff recruitment problem.
\end{abstract}

Keywords-Multi criteria decision making, consistent fuzzy preference relations, fuzzy TOPSIS, z-numbers, intuitive vectorial centroid, human intuition

\section{INTRODUCTION}

Multiple criteria decision making (MCDM) approach has become a discipline of operations research which has been widely explored by experts or practitioners [1]. It is the process of making decision in the appearance of multiple criteria or objectives. Nowadays, uncertainty affected strongly in the world where much of the information on which decisions are based is uncertain [2]. Since the problem of selecting the best alternatives in decision making problems is subject to uncertainty due to imprecision and subjectivity in the decision makers' judgements, fuzzy knowledge represents uncertain information in decision making problems due to flexibility of using linguistic variables. In decision making situation, making choices which depends on numerous factors limited to human ability that is very difficult to deal with [3]. The consideration of fuzzy aspect in MCDM knowledge is significant in order to solve this issue.

In the literature of fuzzy set, Zadeh [4] introduced fuzzy set theory in representing vagueness or imprecision in a mathematical approach. In order to do so, the main motivation of using fuzzy sets shows its ability in appropriately dealing with imprecise numerical quantities and subjective preferences of decision makers [5]. Zadeh [6] proposed a notion of znumbers, which is an order pair of fuzzy numbers $(\tilde{A}, \tilde{B})$. The $\tilde{A}$ component plays the role of a fuzzy restriction and represent the information about an uncertain variable, while the $\tilde{B}$ component is a reliability of $\tilde{A}$ component and enable to represent an idea of certainty or probability [7] [8]. The idea of z-numbers is to provide a basis for computation with numbers which are not completely reliable and more intelligent to describe the knowledge of human being and capable to cater the uncertain information.

In dealing with fuzzy systems, defuzzification plays a significant role in the performance of fuzzy system's modelling [9]. Defuzzification process is guided by the output fuzzy subset that one value would be selected as a single crisp value as the system output. The centroid defuzzification methods of fuzzy numbers have been explored for the last decade. Most of centroid method of fuzzy numbers normally are extracted from geometric aspects where to construct various order relationship from the perspective of membership function to some extent. Fuzzy set theory has done every single part of the official analysis when dealing with the vagueness and imprecision in human decision making. In this paper, the intuitive vectorial centroid defuzzification is introduced and presented into the literature. This centroid method is an improvement of classical vectorial centroid [10]. In this sense, the intuitive vectorial centroid defuzzification is relevant in context of human intuition that capable to consider all possible fuzzy numbers representation properly. This proposed method is incorporated into the development of integrated fuzzy MCDM model. The computational process of intuitive vectorial centroid is illustrated in Section 3.

The latest trend with respect to MCDM is to combine two or more techniques to make up or handle shortcomings appropriately in any single particular technique [11]. In much of the literature, most of the combination or integrated MCDM model combined two techniques in order to tackle the evaluation of criteria and the evaluation of alternatives respectively [12]-[15]. The evaluation process of criteria and alternatives play important role in MCDM techniques requirements. To identify the best decision to be made among 
the various alternatives with several criteria, the methodology has to study the preferences among the criteria to make sure the weights of criteria are reliable enough to be implemented in the selection of alternatives. In this paper, the combination of consistent fuzzy preference relations and fuzzy technique for order of preference by similarity to ideal solution (TOPSIS) using new centroid defuzzification is proposed in dealing with imprecise judgements.

The consistent fuzzy preference relations was proposed by [16] for constructing the decision matrices of pairwise comparisons based on additive transitivity property. In reality, the decision maker is generally unsure of his/ her preferences in partnership selection process because information about the future partners and their performance is incomplete and uncertain. Consistency is crucial for achieving correct solutions in decision process. Due to each positive reciprocal matrix is described by fuzzy numbers in fuzzy linguistic terms, so to satisfy the consistency is very difficult [17]. Beside, establishing a fuzzy positive reciprocal matrix requires $\frac{n \times(n-1)}{2}$ judgments to be made for a level with $n$ criteria.

Hence, the number of comparisons increase with the numbers of criteria, so inconsistent conditions are likely to occur. To solve the consistency problem, the consistent fuzzy preference relations technique is adopted in order to construct fuzzy decision matrix instead of fuzzy positive reciprocal matrix. The utilisation of consistent fuzzy preference relations in this phase yields decision matrices for making pairwise comparison matrices using additive transitivity. There are only $n-1$ comparison judgements are required to ensure consistency on a level that contains $n$ criteria.

According to [18], TOPSIS provides unique way to approach problems, intuitive appealing and easy to understand. In additional, it also represents the rationale of individual choice a scalar value that records both the best and worst alternatives concurrently a straightforward computation algorithm. Fuzzy TOPSIS is an extended version classical TOPSIS with considered fuzzy component as an added value in order to deal with human perceptions. The concept of fuzzy TOPSIS is the most preferred alternative should have the shortest distance from the fuzzy positive ideal solution (FPIS) and longest distance from the fuzzy negative ideal solution (FNIS) [19]. Fuzzy TOPSIS at present offers a solution for decision makers when dealing with real world data that are usually multi criteria and involves a complex decision making process. Regarding to the level of interaction of with decision makers to imprecise data collection, fuzzy TOPSIS provides good agility in decision process.

The MCDM techniques always deal with unbalanced and changeable data inputs. Therefore, sensitivity analysis after the problem solving that can effectively contribute to making accurate decisions by assuming that a set of weights for criteria or alternatives then obtained a new round of weights for them, so that the efficiency of alternatives has become equal or their order has changed [20]. Sensitivity analysis is valuable tool for identifying important models parameters, testing the model conceptualization, and improving the model structure [21]. It clearly indicates that the sensitivity analysis calculates the changing in the final score of alternatives when a change is occurred in the weights of alternatives. Sensitivity analysis can be beneficial for the wide range of purposes including [22]: test the robustness of the results of a model or system in the presence of uncertainty; increase understanding of the relationship between input and output variable in a model or system; uncertainty reduction; ease the calibration stage. In this paper, sensitivity analysis is applied to validate the proposed model

In real world decision making problems, linguistic variables tend to be very complex to handle but makes more sense than classical fuzzy numbers [8]. Rather than use classical fuzzy numbers, the linguistic scales of the proposed integrated consistent fuzzy preference relations and TOPSIS is expressed in a more details and flexible way by $\mathrm{z}$-number. The membership function of type- 1 and type- 2 fuzzy sets have no information regarding knowledge of human being. This issue motivate us to proposed hybrid MCDM model that has capability to handle knowledge of human being and uncertain information properly using z-numbers. The proposed model is constructed without losing the generality of the consistent fuzzy preference relations and fuzzy TOPSIS for z-numbers (Z-CFPR-TOPSIS). The rest of this paper is organised as follows: Section II introduces the concepts of z-numbers, intuitive vectorial centroid defuzzification. Section III views the methodology of intuitive vectorial centroid method for $\mathrm{z}$ numbers and the integration consistent fuzzy preference relations and fuzzy TOPSIS that incorporated with intuitive vectorial centroid method. Section IV discusses a case study in MESSRS SAPRUDIN, IDRIS \& CO Company to demonstrate the feasibility of the hybrid model. Section V summarises the conclusion.

\section{PRELIMINARIES}

In this section, we briefly review some basic concepts and definitions that are illustrated as follows.

\section{A. Z-numbers}

A z-number is an ordered pair of fuzzy numbers

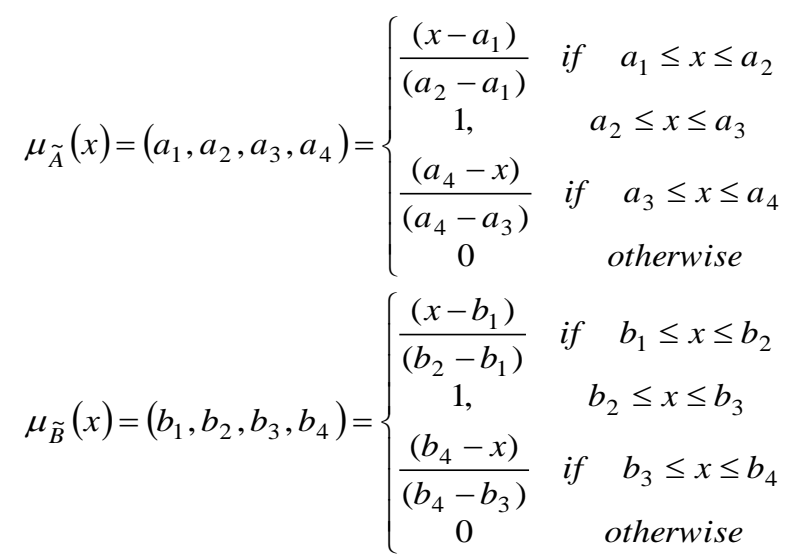

denoted as $Z=(\tilde{A}, \tilde{B})$. First component, $\tilde{A}$ is known as restriction component whereby it is a real-valued uncertain on $X$ while second component, $\tilde{B}$ is a measure of reliability for $\tilde{A}[6]$. The illustration for z-number is depicted in Fig. 1 [7]. 

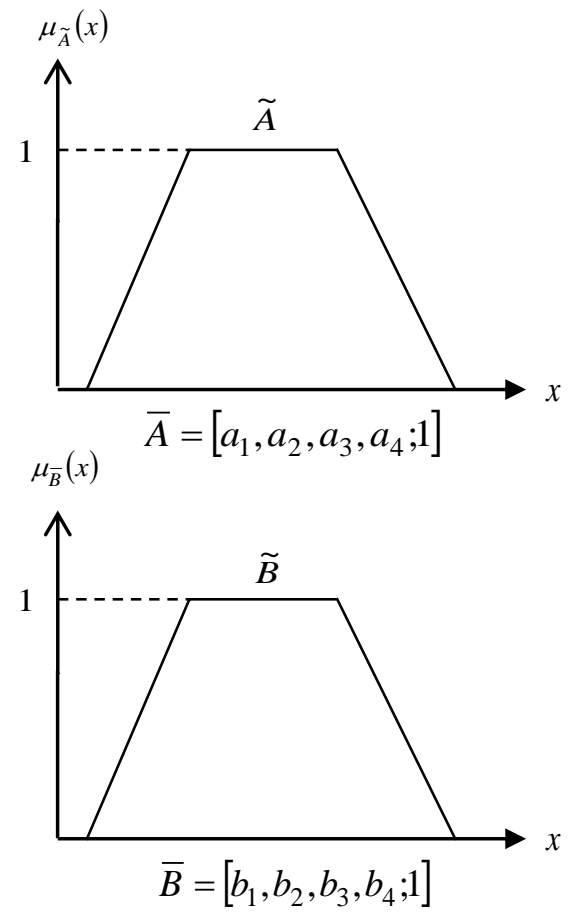

Fig. 1: Z-number, $Z=(\tilde{A}, \tilde{B})$

\section{PROPOSED Methodology}

As noted in the introduction, z-numbers are widely applied in many research areas to deal with uncertain information in data analysis which consistent with human intuition. Most of researchers attempt to eliminate the need of human intuition in data analysis processes. Human intuition is strictly can't be eliminated because it can lead us towards uncertain problems. This section focuses on the development of hybrid MCDM model that incorporated with intuitive vectorial centroid. The proposed methodology consist of two stages as illustrated below.

\section{A. Stage one}

The development of intuitive vectorial centroid defuzzification methodology for z-numbers.

The intuitive vectorial centroid is an extension of the classical vectorial centroid methods for fuzzy numbers that proposed by [10]. The concept is similar like other centroid methods, to find the best centre point of fuzzy number that represent in crisp value or single value. Compare to other centroid methods, the way to get the value is more intelligent manner, easy to compute, more balance, and consider all feasible cases of fuzzy number.

Let $\tilde{A}=\left(a_{1}, a_{2}, a_{3}, a_{4} ; h_{A}\right)$ as the generalised trapezoidal fuzzy number. The method process for intuitive vectorial centroid is showed as follows:
Step 1: Find the centroids of the three parts of $\alpha, \beta$ and $\gamma$ in trapezoid plane representation as shown in Fig 2.

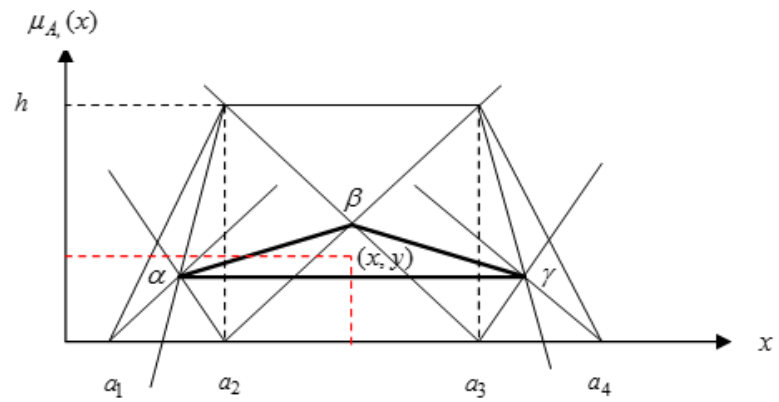

Fig 2: Intuitive vectorial centroid representation

$$
\begin{aligned}
& \alpha\left(x_{\tilde{A}}, y_{\tilde{A}}\right)=\left(a_{1}+\left[\frac{2}{3}\left(a_{2}-a_{1}\right)\right], \frac{h_{\tilde{A}}}{3}\right) \\
& \beta\left(x_{\tilde{A}}, y_{\tilde{A}}\right)=\left(\frac{a_{2}+a_{3}}{2}, \frac{h_{\tilde{A}}}{2}\right) \\
& \gamma\left(x_{\tilde{A}}, y_{\tilde{A}}\right)=\left(a_{4}+\left[\frac{2}{3}\left(a_{3}-a_{4}\right)\right], \frac{h_{\tilde{A}}}{3}\right)
\end{aligned}
$$

Step 2: Connect all vertices centroids points of $\alpha, \beta$ and $\gamma$ each other, where it will create another triangular plane inside of trapezoid plane.

Step 3: The centroid index of intuitive vectorial centroid of $(\tilde{x}, \tilde{y})$ with vertices $\alpha, \beta$ and $\gamma$ can be calculated as

$$
\begin{array}{r}
\operatorname{IVC}\left(\tilde{x}_{\tilde{A}}, \tilde{y}_{\tilde{A}}\right)=\left(\beta\left(\tilde{x}_{\tilde{A}}\right)+\left[\frac{2}{3}\left(\frac{\alpha\left(\tilde{x}_{\tilde{A}}\right)+\gamma\left(\tilde{x}_{\tilde{A}}\right)}{2}-\beta\left(\tilde{x}_{\tilde{A}}\right)\right)\right], \ldots\right. \\
\left.\ldots \beta\left(\tilde{y}_{\tilde{A}}\right)+\left[\frac{2}{3}\left(\frac{\alpha\left(\tilde{y}_{\tilde{A}}\right)+\gamma\left(\tilde{y}_{\tilde{A}}\right)}{2}-\beta\left(\tilde{y}_{\tilde{A}}\right)\right)\right]\right)
\end{array}
$$

Intuitive vectorial centroid can be summarised as

$$
\operatorname{IVC}\left(\tilde{x}_{\tilde{A}}, \tilde{y}_{\tilde{A}}\right)=\left(\frac{2\left(a_{1}+a_{4}\right)+7\left(a_{2}+a_{3}\right)}{18}, \frac{7 h_{\tilde{A}}}{18}\right)
$$

where

$\alpha$ : the centroid coordinate of first triangle plane

$\beta$ : the centroid coordinate of rectangle plane

$\gamma:$ the centroid coordinate of second triangle plane

$\tilde{x}$ : the centroid point on the horizontal $x$-axis

$\tilde{y}$ : the centroid point on the vertical $y$-axis

$(\tilde{x}, \tilde{y}):$ the centroid coordinate of fuzzy number $\tilde{A}$

Centroid index of intuitive vectorial centroid can be generated using Euclidean Distance by [23] as

$$
R(\tilde{A})=\sqrt{\tilde{x}^{2}+\tilde{y}^{2}}
$$


Assume a z-number, $Z=(\tilde{A}, \tilde{B})$, which is describe in Fig. 1. Let $\tilde{A}=\left\{\left\langle x, u_{\tilde{A}}(x)\right\rangle \mid x \in[0,1]\right\} \quad$ and $\quad \tilde{B}=\left\{\left\langle x, u_{\tilde{B}}(x)\right\rangle \mid x \in[0,1]\right\}$, $u_{\tilde{A}}(x)$ and $u_{\tilde{B}}(x)$ are trapezoidal membership function.

Step 1: Converting the reliability component on $x$-coordinate into crisp number or weight using intuitive vectorial centroid method from equation (6).

$$
I V C_{\tilde{B}}(\tilde{x})=\frac{2\left(b_{1}+b_{4}\right)+7\left(b_{2}+b_{3}\right)}{18}=\alpha
$$

Step 2: Add the weight of reliability component to the restriction component. The weighted $\mathrm{z}$-number can be denoted as $\tilde{Z}^{\alpha}=\left\{\left\langle x, \mu_{\widetilde{B}^{\alpha}}(x)\right\rangle \mid \mu_{\widetilde{B}^{\alpha}}(x)=\alpha \mu_{\widetilde{B}^{\alpha}}(x), x \in[0,1]\right\}$

\section{Theorem 1:}

$$
E_{\tilde{A}^{\alpha}}(x)=\alpha E_{\tilde{A}}(x), \quad x \in X
$$

Subject to:

$$
\mu_{\tilde{A}^{\alpha}}(x)=\alpha \mu_{\tilde{A}^{\alpha}}(x), \quad x \in X
$$

Proof:

$$
\begin{aligned}
& E_{\tilde{A}^{\alpha}}(x)=\left[a_{1}, a_{2}, a_{3}, a_{4} ; \frac{2\left(b_{1}+b_{4}\right)+7\left(b_{2}+b_{3}\right)}{18}\right]=\left[a_{1}, a_{2}, a_{3},\right. \\
& \left.a_{4} ; \alpha\right]=\alpha E_{\tilde{A}}(x)
\end{aligned}
$$

which can be denoted by the Fig. 3 [7]

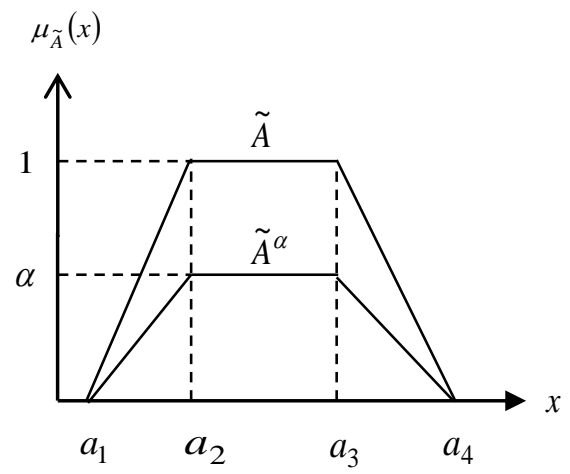

Fig. 3: Z-number after multiplying the reliability

Step 3: Convert the irregular fuzzy number (weighted restriction) to regular fuzzy number that denoted as $\tilde{Z}^{\prime}=\left\{\left\langle x, \mu_{\tilde{Z}^{\prime}}(x)\right\rangle \mid \mu_{\tilde{Z}^{\prime}}(x)=\mu_{\tilde{A}}(\sqrt{\alpha} x), x \in[0,1]\right\}$. In accordance with the theorem 3 , the conclusion can be made that $\tilde{Z}^{\prime}$ has the same fuzzy expectation with $\tilde{Z}^{\alpha}$ where both are equal with fuzzy expectation.

\section{Theorem 2:}

$$
E_{\tilde{Z}^{\prime}}(x)=\alpha E_{\tilde{A}}(x), \quad x \in \sqrt{\alpha} X
$$

Subject to:

$$
\mu_{\tilde{Z}^{\prime}}(x)=\mu_{\tilde{A}}(\sqrt{\alpha} x), \quad x \in \sqrt{\alpha} X
$$

\section{Proof:}

$E_{\tilde{Z}^{\prime}}(x)=\left[a_{1}, a_{2}, a_{3}, a_{4} ; \sqrt{\frac{2\left(b_{1}+b_{4}\right)+7\left(b_{2}+b_{3}\right)}{18}}\right]=\left[a_{1}, a_{2}, a_{3}\right.$, $\left.a_{4} ; \sqrt{\alpha}\right]=\sqrt{\alpha} E_{\tilde{A}}(x)$

which can be denoted by the Fig. 4 below [7]

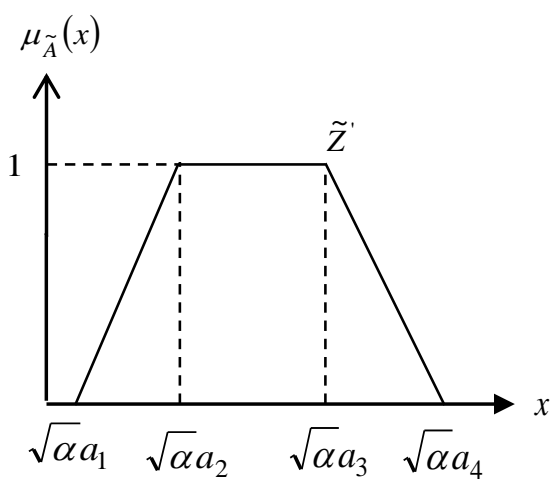

Fig. 4: The regular fuzzy number transformed from z-number

Theorem 3:

$$
E_{\widetilde{Z}^{\prime}}(x)=E_{\widetilde{A}^{\alpha}}(x)
$$

Proof:

$$
\begin{aligned}
& E_{\widetilde{A}^{\alpha}}(x)=\alpha E_{\tilde{A}^{\prime}}(x) \\
& E_{\widetilde{Z}^{\prime}}(x)=\alpha E_{\tilde{A}}(x) \\
& E_{\widetilde{Z}^{\prime}}(x)=E_{\widetilde{A}^{\alpha}}(x)
\end{aligned}
$$

\section{B. Stage two}

The development of hybrid fuzzy consistent fuzzy preference relations - fuzzy TOPSIS using the intuitive vectorial centroid

The methodology of proposed hybrid fuzzy MCDM model consist of four phases as illustrated below in Fig. 5.

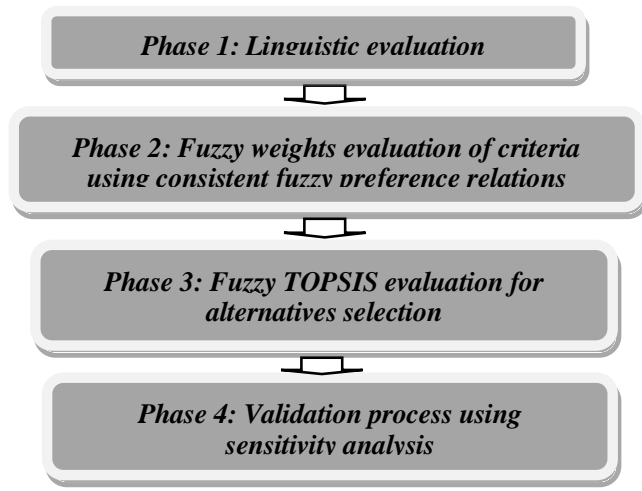

Fig. 5: Hybrid consistent fuzzy preference relations - fuzzy TOPSIS framework

\section{Phase 1: Linguistic Evaluation}

The fuzzy linguistic terms are used to present the important of criteria preferences based on $\mathrm{z}$-numbers. These preferences are 
computed using consistent fuzzy preferences. For fuzzy TOPSIS evaluation, another fuzzy linguistic terms are used to represent the evaluating values of the alternatives with respect to difference criteria with degree of confidence respectively.

\section{Phase 2: Fuzzy weights evaluation of criteria using consistent} fuzzy preference relations

Step 1: Construct a hierarchy structure.

The construction of hierarchy model needs judgement matrix filled by decision makers about the evaluation of all criteria.

Step 2: Construct a pair-wise comparison matrices

Consistent fuzzy preference relations is adopted to evaluate the weights of difference criteria for the performance of alternatives. The pairwise comparison matrices are constructed among all criteria in the dimension of the hierarchy systems based on the decision makers' preferences in phase 1 as following matrix $A$ :

$A=\left[\begin{array}{cccc}1 & \tilde{a}_{12} & \cdots & \tilde{a}_{1 n} \\ \tilde{a}_{21} & 1 & \cdots & \tilde{a}_{2 n} \\ \vdots & \vdots & \ddots & \vdots \\ \tilde{a}_{n 1} & \tilde{a}_{n 2} & \cdots & 1\end{array}\right]=\left[\begin{array}{cccc}1 & \tilde{a}_{12} & \cdots & \tilde{a}_{1 n} \\ 1 / \tilde{a}_{12} & 1 & \cdots & \tilde{a}_{2 n} \\ \vdots & \vdots & \ddots & \vdots \\ 1 / \tilde{a}_{1 n} & 1 / \tilde{a}_{2 n} & \cdots & 1\end{array}\right]$

Step 3: Convert decision makers' preferences from z-numbers into regular fuzzy numbers.

Conversion process is computed by using equation (13).

$$
\begin{aligned}
& E_{\tilde{Z}}(x)=\left[a_{1}, a_{2}, a_{3}, a_{4} ; \sqrt{\frac{2\left(b_{1}+b_{4}\right)+7\left(b_{2}+b_{3}\right)}{18}}\right]=\left[a_{1}, a_{2}, a_{3},\right. \\
& \left.a_{4} ; \sqrt{\alpha}\right]=\sqrt{\alpha} E_{\tilde{A}}(x)
\end{aligned}
$$

Step 4: Aggregate the decision makers' preferences.

The pairwise comparison matrices of decision makers' preferences are aggregated using equation below:

$$
\tilde{a}_{i j}=\left(\tilde{a}_{i j}^{1} \times \tilde{a}_{i j}^{2} \times \ldots \times \tilde{a}_{i j}^{n}\right)^{1 / k}
$$

where $k$ is the number of decision makers and $i=1,2, \ldots m$; $j=1,2, \ldots n$.

Step 5: Defuzzify the fuzzy numbers of aggregation's result of decision makers' preferences.

Intuitive vectorial centroid for z-numbers is used for conversion process using equation below.

$$
\operatorname{IVC}\left(\tilde{x}_{\tilde{A}, \tilde{R}}, \tilde{y}_{\tilde{A}, \tilde{R}}\right)=\left(\frac{2\left(\sqrt{\varphi} a_{1}+\sqrt{\varphi} a_{4}\right)+7\left(\sqrt{\varphi} a_{2}+\sqrt{\varphi} a_{3}\right)}{18}, \frac{7 h_{\tilde{A}, \tilde{R}}}{18}\right)
$$

Step 6: Compute the criteria values as weightage for alternatives' evaluation using consistent fuzzy preference relations.

In order to avoid misleading solutions in expressing the decision makers' opinions, the study of consistency by means of preference relations becomes a very important aspect. In decision making problems based on fuzzy preference relations, the study of consistency is associated with the study of transitivity properties. In this study, the new characterisation of consistency property defined by the additive transitivity property of fuzzy preference relation is developed.

Consistent fuzzy preference relations was proposed by [16] for constructing the decision matrices of pairwise comparisons based on additive transitivity property. Referring to [24], a fuzzy preference relation $R$ on the set of the criteria or alternatives $A$ is a fuzzy set stated on the Cartesian product set $A \times A$ with the membership function $\mu_{R}: A \times A \rightarrow[0,1]$. The preference relation is denoted by $n \times n$ matrix $R=\left(r_{i j}\right)$ where $r_{i j}=\mu_{R}\left(a_{i}, a_{j}\right) \forall i, j \in\{1, \ldots, n\}$. The preference ratio, $r_{i j}$ of the alternative $a_{i}$ to $a_{j}$ is determined by

$$
r_{i j}= \begin{cases}0.5 & a_{i} \text { is different to } a_{j} \\ (0.5,1) & a_{i} \text { is preferred than } a_{j} \\ 1 & a_{i} \text { is absolutely preferred than } a_{j}\end{cases}
$$

The preference matrix $R$ is presumed to be additive reciprocal, $p_{i j}+p_{j i}=1, \forall i, j \in\{1, \ldots, n\}$. Several propositions are associated to the consistent additive preference relations as follows:

Proposition 1 [25]: Consider a set of criteria or alternatives, $X=\left\{x_{1}, \ldots, x_{n}\right\}$, and associated with a reciprocal multiplicative preference relation $A=\left(a_{i j}\right)$ for $a_{i j} \in\left[\frac{1}{9}, 9\right]$. Then, the corresponding reciprocal fuzzy preference relation, $P=\left(p_{i j}\right)$ with $p_{i j} \in[0,1]$ associated with $A$ is given by the following formulation

$$
p_{i j}=g\left(a_{i j}\right)=\frac{1}{2}\left(1+\log _{9} a_{i j}\right)
$$

Generally, if $a_{i j} \in\left[\frac{1}{n}, n\right]$, then $\log _{n} a_{i j}$ is used, in particular, when $a_{i j} \in\left[\frac{1}{9}, 9\right] ; \log _{9} a_{i j}$ is considered as in the above proposition because $a_{i j}$ is between $\frac{1}{9}$ and 9. If $a_{i j}$ is between $\frac{1}{7}$ and 7 , then $\log _{7} a_{i j}$ is used.

Proposition 2 [25]: For a reciprocal fuzzy preference relation $P=\left(p_{i j}\right)$, the following statements are equivalent

$$
\text { (1) } p_{i j}+p_{j k}+p_{k i}=\frac{3}{2}, \forall i, j, k
$$


(2) $p_{i j}+p_{j k}+p_{k i}=\frac{3}{2}, \forall i<j<k$

Proposition 3 [25]: For a reciprocal fuzzy preference relation $P=\left(p_{i j}\right)$, the following statements are equivalent

$$
\begin{aligned}
& \text { (1) } p_{i j}+p_{j k}+p_{k i}=\frac{3}{2}, \forall i<j<k \\
& \text { (2) } p_{i(i+1)}+p_{(i+1)(i+2)}+\ldots+p_{(j-1) j}+p_{j i}=\frac{j-i+1}{2}, \\
& \forall i<j
\end{aligned}
$$

Proposition 3 is crucial because it can be used to construct a consistent fuzzy preference relations form the set of $n-1$ values $\left\{p_{12}, p_{23}, \ldots, p_{n-1}\right\}$. A decision matrix with entries that are not in the interval $[0,1]$, but in an interval $[-c, 1+c]$, $c>0$, can be obtained by transforming the obtained values using a transformation function that preserves reciprocity and additive consistency with the function

$$
f:[-c, 1+c] \rightarrow[0,1], f(x)=\frac{(x+c)}{(1+2 c)}
$$

\section{Phase 3: Fuzzy TOPSIS evaluation for alternatives selection}

Step 1: Determine the weights of evaluation criteria.

The weighting of evaluation criteria are employed from consistent fuzzy preference relations process before.

Step 2: Construct the fuzzy decision matrix for alternatives' evaluation using fuzzy TOPSIS.

Concept of TOPSIS method originally proposed by [19]. They claimed that the alternative should not be chosen based on having the shortest distance from the positive ideal reference point (PIRT) only, but also have the longest distance from the negative ideal reference point (NIRP) in solving the MCDM problems. Here, the proposed methodology for fuzzy TOPSIS is illustrated differ from others in terms of the usage of defuzzification method, normalization process and ranking process.

The fuzzy decision matrix is constructed and the linguistic terms from Table 2 is used to evaluate the alternatives with respect to criteria. Then, aggregate DMs' preferences:

$$
\overline{D M}=\begin{gathered}
A_{1} C_{1} \\
A_{2} \\
\vdots \\
A_{m}
\end{gathered}\left[\begin{array}{cccc}
\tilde{x}_{11} & \tilde{x}_{12} & \cdots & C_{n} \\
\tilde{x}_{21} & \tilde{x}_{22} & \cdots & \tilde{x}_{2 n} \\
\vdots & \vdots & \ddots & \vdots \\
\tilde{x}_{m 1} & \tilde{x}_{m 1} & \cdots & \tilde{x}_{m n}
\end{array}\right]
$$

$i=1,2, \ldots, m ; j=1,2, \ldots, n$ and $\tilde{x}_{i j}=\frac{1}{K}\left(\tilde{x}_{i j}^{1} \oplus,,, \oplus \tilde{x}_{i j}^{k} \oplus,,, \tilde{x}_{i j}^{K}\right)$

where $\tilde{x}_{i j}$ is the performance rating of alternatives, $A_{i}$ with respect to criterion $C_{j}$ evaluated by $k t h$ experts and $\tilde{x}_{i j}=\left(a_{1}^{k}, a_{2}^{k}, a_{3}^{k}, a_{4}^{k} ; h^{k}\right)$.
Step 3: Fuzzy decision matrix is weighted and normalised. Then, defuzzify the standardised generalised fuzzy numbers into coordinate form, $(\tilde{x}, \tilde{y})$. The weighted fuzzy normalised decision matrix is denoted by $\tilde{V}$ as depicted below with numerical example:

$$
\tilde{V}=\left[\tilde{v}_{i j}\right]_{m \otimes n} ; \quad i=1,2, \ldots, m ; \quad j=1,2, \ldots, n
$$

where

$$
\tilde{v}_{i j}=\tilde{x}_{i j} \times \tilde{w}_{j}
$$

Normalised each generalised trapezoidal fuzzy numbers into standardised generalised fuzzy numbers using [26]

$$
\begin{aligned}
& a_{1_{1}}^{\prime}=\frac{a_{1}-\min \left(a_{1}, b_{1}\right)}{\max \left(a_{4}, b_{4}\right)-\min \left(a_{1}, b_{1}\right)}, \\
& a_{2^{\prime}}^{\prime}=\frac{a_{2}-\min \left(a_{1}, b_{1}\right)}{\max \left(a_{4}, b_{4}\right)-\min \left(a_{1}, b_{1}\right)}, \\
& a_{3}^{\prime}=\frac{a_{3}-\min \left(a_{1}, b_{1}\right)}{\max \left(a_{4}, b_{4}\right)-\min \left(a_{1}, b_{1}\right)}, \\
& a_{1^{\prime}}^{\prime}=\frac{a_{4}-\min \left(a_{1}, b_{1}\right)}{\max \left(a_{4}, b_{4}\right)-\min \left(a_{1}, b_{1}\right)},
\end{aligned}
$$

The weights from consistent fuzzy preference relations are adopted here. Defuzzify the standardised generalised fuzzy numbers using intuitive vectorial centroid, then translate them into the index point proposed by [27] as shown as follows:

$$
\begin{gathered}
x_{\tilde{A}_{i}^{*}}=x_{\tilde{A}_{i}^{*}} \\
y_{\tilde{A}_{i}^{s}}=0.5 \times h_{\tilde{A}_{i}}-y_{\tilde{A}_{i}^{*}} \times S T D_{\tilde{A}_{i}}
\end{gathered}
$$$$
\text { where spread, } S T D_{\tilde{A}_{i}}=\sqrt{\frac{\sum_{j=1}^{4}\left(a_{i j}^{*}-x_{\tilde{A}_{i}^{*}}\right)}{n-1}}
$$

Use the new point of $y_{\tilde{A}_{i}^{*}}$ to compute fuzzy positive-ideal solution and fuzzy negative-ideal solution.

Step 4: Determine the fuzzy positive-ideal solution (FPIS) and fuzzy negative-ideal solution (FNIS).

Referring to normalise trapezoidal fuzzy weights, the FPIS, $A^{+}$ represents the compromise solution while FNIS, $A^{-}$represents the worst possible solution. The range belong to the closed interval $[0,1]$. The FPIS $A^{+}$(aspiration levels) and FNIS $A^{-}$ (worst levels) as follows.

$$
A^{+}=[1,1,1,1 ; 1] \quad A^{-}=[-1,-1,-1,-1 ; 1]
$$

The FPIS, $A^{+}$and FNIS, $A^{-}$can be obtained by centroid method for $\left(x_{A^{+}}, y_{A^{+}}\right)$and $\left(x_{A^{-}}, y_{A^{-}}\right)$.

Step 5: Calculate the distance of each alternative from FPIS and FNIS. 
The distance $\tilde{d}_{i}^{+}$and $\tilde{d}_{i}^{-}$of each alternative from formulation $A^{+}$and $A^{-}$can be calculated by the area of compensation method

$$
\begin{aligned}
& \bar{d}_{i}^{+}\left(\tilde{v}_{i j}, \tilde{v}_{j}^{+}\right)=\sqrt{\left(x_{\tilde{A}_{i}^{*}}-x_{A^{+}}\right)^{2}+\left(y_{\tilde{A}_{i}^{*}}-y_{A^{+}}\right)^{2}} \\
& \bar{d}_{i}^{-}\left(\tilde{v}_{i j}, \tilde{v}_{j}^{-}\right)=\sqrt{\left(x_{\tilde{A}_{i}^{*}}-x_{A^{-}}\right)^{2}+\left(y_{\tilde{A}_{i}^{*}}-y_{A^{-}}\right)^{2}}
\end{aligned}
$$

Step 6: Find the closeness coefficient, $C C_{i}$ and improve alternatives for achieving aspiration levels in each criteria. The decision rules for five classes are depicted in Table 1. Notice that the highest $C C_{i}$ value is used to determine the rank.

$$
\overline{C C}_{i}=\frac{\bar{d}_{i}^{-}}{\bar{d}_{i}^{+}+\bar{d}_{i}^{-}}=1-\frac{\bar{d}_{i}^{+}}{\bar{d}_{i}^{+}+\bar{d}_{i}^{-}}
$$

where, $\frac{\bar{d}_{i}^{-}}{\overline{\bar{d}}_{i}^{+}+\bar{d}_{i}^{-}}$is satisfaction degree in ith alternative and $\frac{\bar{d}_{i}^{+}}{\overline{\bar{d}}_{i}^{+}+\bar{d}_{i}^{-}}$is fuzzy gaps degree in ith alternative.

Fuzzy gap should be improvised for reaching aspiration levels and get the best mutually beneficial strategy from among a fuzzy set of feasible alternatives.

\section{Phase 4: Validation process using sensitivity analysis}

Sensitivity analysis can effectively contributes in making accurate decisions by assuming that a set of weights for criteria or alternatives then obtained a new round of weights for them, so that the efficiency of alternatives has become equal or their order has changed. The results of MCDM models are importantly needed to validate using sensitivity analysis method to analyse the quality and how robustness of MCDM model to reach a right decision under different conditions. In this paper, sensitivity analysis technique by [20] is utilised.

\section{CASE STUDY}

A legal company in Malaysia, MESSRS SAPRUDIN, IDRIS \& CO plans to recruit new staff from the several applicants/ candidate in some aspects with the lowest of him/ her to resign.
There are three decision makers (DMs) DM1, DM2, and DM3 of a firm to evaluate the candidates and four candidates or alternatives $\mathrm{x} 1, \mathrm{x} 2, \mathrm{x} 3$ and $\mathrm{x} 4$. Several criteria are considered to evaluate the candidates which are: Emotional steadiness $\left(\mathrm{C}_{1}\right)$, Oration $\left(\mathrm{C}_{2}\right)$, Personality $\left(\mathrm{C}_{3}\right)$, Past experience $\left(\mathrm{C}_{4}\right)$ and, Selfconfidence $\left(\mathrm{C}_{5}\right)$. These criteria are used based on [28]. This study simplify the concept of attributes to $\mu_{\tilde{A}} \in[0,1]$ for fuzzy events. The values of attributes correspond to $\mathrm{z}$-numbers. The proposed model is compared with Z-AHP [8] and Z-TOPSIS [29] from the literature for comparative study.

\section{Phase 1: Linguistic evaluation}

The decision makers use the linguistic terms as depicted in Table 1 to present the weights using consistent fuzzy preference relations evaluation. The linguistic terms in Table 1 present the important of criteria preferences. In Table 2, the decision makers (DMs) use the linguistic terms for fuzzy TOPSIS evaluation to represent the evaluating values of the alternatives with respect to difference criteria with degree of confidence (reliability) respectively as shown in Table 3 .

\section{Phase 2: Fuzzy weights evaluation using consistent fuzzy preference relations}

Step 1: Construct a hierarchy structure.

The construction of hierarchy model needs judgement matrix filled by DMs about the evaluation of all criteria (Fig. 6).

Step 2: Construct a pair-wise comparison matrices.

Consistent fuzzy preference relations is adopted to evaluate the weights of difference criteria for the performance of alternatives. The pair-wise comparison matrices are constructed among all criteria in the dimension of the hierarchy systems based on the DMs' preferences in phase 1 using equation (18) that are depicted in Fig. 7, 8 and 9.

Step 3: Convert the z-number into regular fuzzy number and aggregate DMs' preferences.

Before aggregate the DMs' preferences, convert the $\mathrm{z}$ numbers into regular numbers using equation (13) that are depicted in Fig. 9, 10 and 11.

Table 1. Trapezoidal fuzzy numbers preference scale [30]

\begin{tabular}{lcll}
\hline Linguistic variables & $\begin{array}{l}\text { Scale of relative important of } \\
\text { crisp numbers }\end{array}$ & Trapezoidal fuzzy numbers & $\begin{array}{l}\text { Reciprocal trapezoidal } \\
\text { fuzzy number }\end{array}$ \\
\hline Equally important (EI) & 1 & $(1,1,1,1 ; 1)$ & $(1,1,1,1 ; 1)$ \\
Intermediate value (IV) & 2 & $(1,3 / 2,5 / 2,3 ; 1)$ & $(1 / 3,2 / 5,2 / 3,1 ; 1)$ \\
Moderately more important (MMI) & 3 & $(2,5 / 2,7 / 2,4 ; 1)$ & $(1 / 4,2 / 9,2 / 5,1 / 2 ; 1)$ \\
Intermediate value (IV) & 4 & $(3,7 / 2,9 / 2,5 ; 1)$ & $(1 / 5,2 / 9,2 / 7,1 / 3 ; 1)$ \\
Strongly more important (SMI) & 5 & $(4,9 / 2,11 / 2,6 ; 1)$ & $(1 / 6,2 / 11,2 / 9,1 / 4 ; 1)$ \\
Intermediate value (IV) & 6 & $(5,11 / 2,13 / 2,7 ; 1)$ & $(1 / 7,2 / 13,2 / 11,1 / 5 ; 1)$ \\
Very strong more important (VSMI) & 7 & $(6,13 / 2,15 / 2,8 ; 1)$ & $(1 / 8,2 / 15,2 / 13,1 / 6 ; 1)$ \\
Intermediate value (IV) & 8 & $(7,15 / 2,17 / 2,9 ; 1)$ & $(1 / 9,2 / 17,2 / 15,1 / 7 ; 1)$ \\
Extremely more important (EMI) & 9 & $(8,17 / 2,9,9 ; 1)$ & $(1 / 9,1 / 9,2 / 17,1 / 8 ; 1)$ \\
\hline
\end{tabular}


Table 2. Linguistic terms and their corresponding generalised fuzzy numbers [30]

\begin{tabular}{ll}
\hline Linguistic terms & Generalised fuzzy numbers \\
\hline Absolutely-low (AL) & $(0.0,0.0,0.0,0.0 ; 1)$ \\
Very-low (VL) & $(0.0,0.0,0.02,0.07 ; 1)$ \\
Low (L) & $(0.04,0.10,0.18,0.23 ; 1)$ \\
Fairly-low (FL) & $(0.17,0.22,0.36,0.42 ; 1)$ \\
Medium (M) & $(0.32,0.41,0.58,0.6 ; 1)$ \\
Fairly-high (FH) & $(0.58,0.63,0.80,0.86 ; 1)$ \\
High (H) & $(0.72,0.78,0.92,0.97 ; 1)$ \\
Very-high (VH) & $(0.93,0.98,1.0,1.0 ; 1)$ \\
Absolutely-high (AH) & $(1.0,1.0,1.0,1.0 ; 1)$ \\
\hline
\end{tabular}

Table 3. Reliability linguistic terms and their corresponding $\mathrm{z}-$ numbers [31]

\begin{tabular}{ll}
\hline Linguistic Terms & Generalised fuzzy numbers \\
\hline Very-low (VL) & $(0,0,0,0.25 ; 1)$ \\
Low (L) & $(0,25,0.25,0.5 ; 1)$ \\
Medium (M) & $(0.25,0.5,0.5,0.75 ; 1)$ \\
High (H) & $(0.5,0.75,0.75,1 ; 1)$ \\
Very-high (VH) & $(0.75,1,1,1 ; 1)$ \\
\hline
\end{tabular}

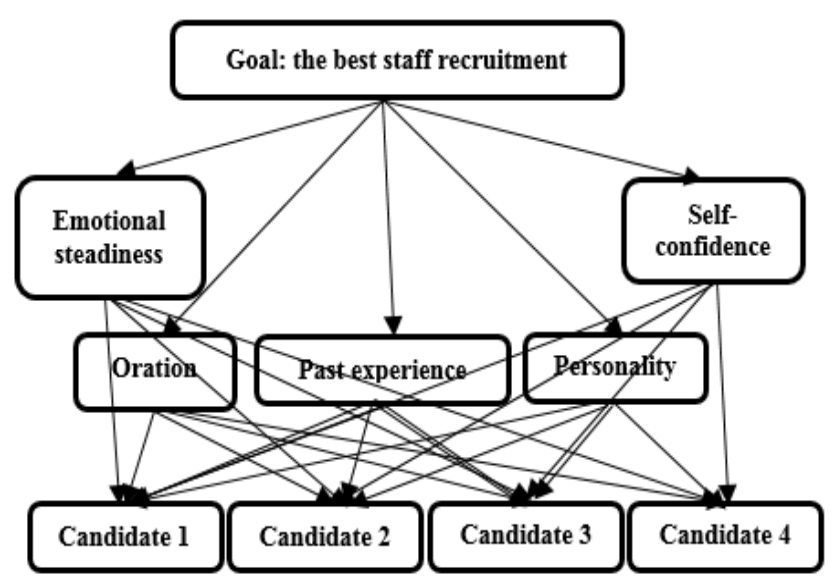

Fig. 6: The hierarchy of staff recruitment problem.

ES

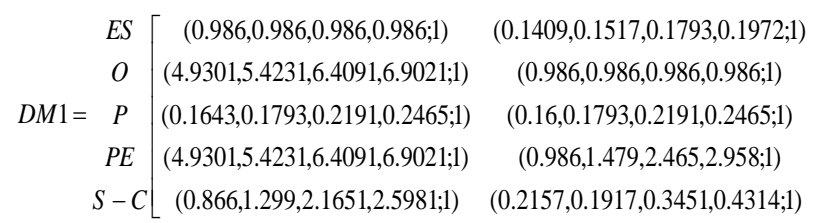

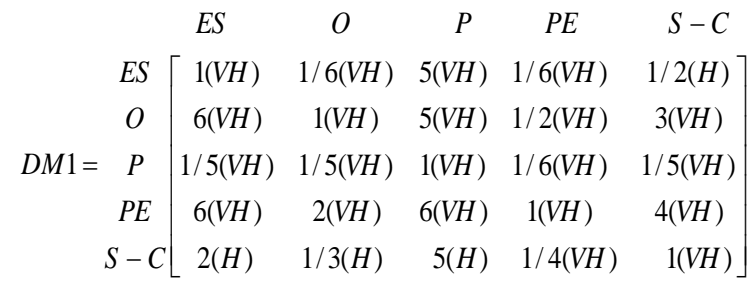

Fig. 7. Pairwise comparison matrix of criteria with reliability component from DM1

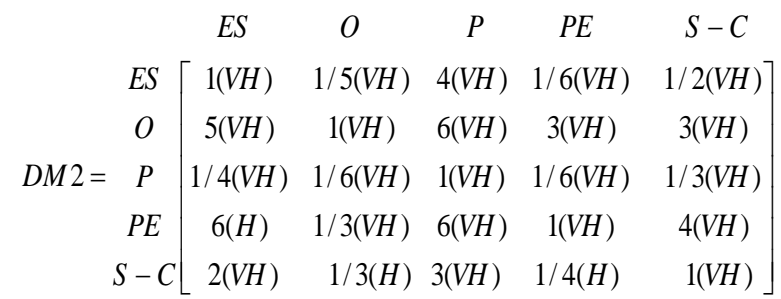

Fig. 8. Pairwise comparison matrix of criteria with reliability component from DM2

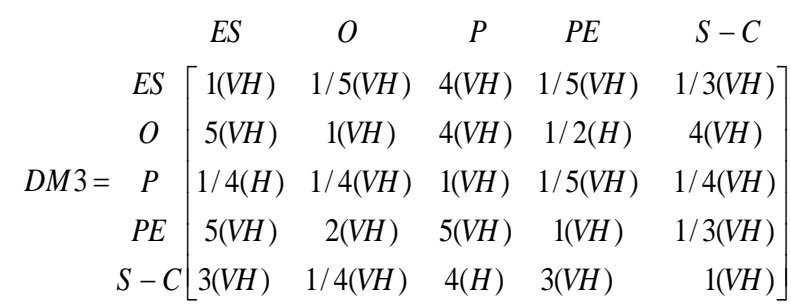

Fig. 9. Pairwise comparison matrix of criteria with reliability component from DM3 Fig. 10. The fuzzy pairwise comparison matrix of DM1 for criteria evaluation after conversion process

$$
\text { ES }
$$

ES $[(0.986,0.986,0.986,0.986 ; 1) \quad(0.1643,0.1793,0.2191,0.2465 ; 1)$

\begin{tabular}{l|lll}
$O$ & $(3.944,4.437,5.423,5.9161 ; 1)$ & $(0.986,0.986,0.986,0.986 ; 1)$
\end{tabular}

$D M 2=P \quad(0.1972,0.2191,0.22817,0.3287 ; 1) \quad(0.1409,0.1517,0.1793,0.1972 ; 1)$

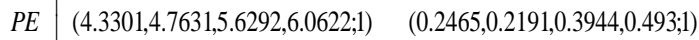

$S-C(0.9860,1.4790,2.4650,2.958 ; 1) \quad(0.2165,0.1925,0.3464,0.4330 ; 1)$
$P$

$(2.958,3.451,4.4371,4.9301 ; 1)$

$(4.9301,5.4231,6.4091,6.9021 ; 1)$

$(0.986,0.986,0.986,0.986 ; 1)$

$(4.9301,5.4231,6.4091,6.9021 ; 1)$

$(1.972,2.465,3.451,3.9441 ; 1)$
$P E$

$(0.1409,0.1517,0.1793,0.1972 ; 1) \quad(0.2887,0.3464,0.5774,0.866 ;, 1)$ $(0.3287,0.3944,0.6573,0.9860 ; 1) \quad(1.972,2.465,3.451,3.944 ; 1)$ $(0.1409,0.1517,0.1793,0.1972 ; 1) \quad(0.1643,0.1793,0.2191,0.2465 ; 1)$ $(0.986,0.986,0.986,0.986 ; 1) \quad(2.958,3.451,4.437,4.930 ; 1)$ $(0.1972,0.2191,0.2817,0.2817,0.3287 ; 1) \quad(0.986,0.986,0.986,0.98 ; 1)$

$(0.1409,0.1517,0.1793,0.1972 ; 1) \quad(0.3287,0.3944,0.6573,0.986 ; 1)$ $(1.972,2.465,3.451,3.9144 ; 1) \quad(1.972,2.465,3.451,3.944 ; 1)$ $(0.1409,0.1517,0.1793,0.1972 ; 1) \quad(0.2465,0.2191,0.3944,0.493 ; 1)$ $(0.986,0.986,0.986,0.986 ; 1) \quad(2.958,3.451,4.4371,4.9301 ; 1)$ $(0.1732,0.125,0.2474,0.2887 ; 1) \quad(0.986,0.986,0.986,0.986 ; 1)$

Fig. 11. The fuzzy pairwise comparison matrix of DM2 for criteria evaluation after conversion process 


\begin{tabular}{|c|c|c|c|c|c|c|}
\hline & $E S$ & $(0.986,0.986,0.986,0.986 ; 1)$ & $(0.1643,0.1793,0.2191,0.2465 ; 1)$ & $(2.958,3.451,4.437,4.930 ; 1)$ & $(0.1643,0.1793,0.2191,0.2465 ; 1)$ & $(0.2465 .0 .2191 .0 .3944 .0 .4930 ; 1)$ \\
\hline & $O$ & $(3.9441,4.4371,5.4231,5.9161 ; 1)$ & $(0.986,0.986,0.986,0.986 ; 1)$ & $(2.958,3.451,4.437,4.930 ; 1)$ & $(0.2887,0.3464,0.5774,0.8660 ; 1)$ & $(2.958,3.451,4.4371,4.9301 ; 1)$ \\
\hline$D M 3=$ & $P$ & $(0.1732,0.1925,0.2474,0.2887 ; 1)$ & $(0.1972,0.2191,0.2817,0.3287 ; 1)$ & $(0.986,0.986,0.986,0.986 ; 1)$ & $(0.1643,0.1793,0.2191,0.2465 ; 1)$ & $(0.1972,0.2191,0.2817,0.3287 ; 1)$ \\
\hline & $P E$ & $(3.9441,4.4371,5.4231,5.9161 ; 1)$ & $(0.986,1.479,2.465,2.958 ; 1)$ & $(3.9441,4.4371,5.4231,5.9161 ; 1)$ & $(0.986,0.986,0.986,0.986 ; 1)$ & $(0.2465,0.2191,0.3944,0.4930 ; 1)$ \\
\hline & $S-C$ & $(1.9720,2.465,3.451,3.9441 ; 1)$ & $(0.1972,0.2191,0.2817,0.3287 ; 1)$ & $(2.5981,3.0311,3.8971,4.3301 ; 1)$ & $(1.972,2.465,3.451,3.9441 ; 1)$ & $(0.986,0.986,0.986,0.98 ; 1)$ \\
\hline
\end{tabular}

Fig. 12. The fuzzy pairwise comparison matrix of DM3 for criteria evaluation after conversion process

Step 4: Aggregate the decision makers' preferences. The aggregated pairwise comparison matrix for each criterion is presented in Fig. 13 as below.

$$
\text { ES }
$$

$$
\begin{array}{r}
E S\left[\begin{array}{c}
(0.986,0.986,0.986,0.986 ; 1) \\
O \\
\text { Aggregated }= \\
P \\
P E
\end{array}\right] \begin{array}{c}
(4.2486,4.744,5.7336,6.228 ; 1) \\
(4.3829,4.8575,5.8054,6.2789 ; 1) \\
(4.3829,4.8575,5.8054,6.2789 ; 1) \\
(1.1897,1.6793,2.6409,3.1179 ; 1) \\
P E
\end{array} \\
\quad(0.1483,0.1604,0.1917,0.2124 ; 1) \\
\quad(0.5720,0.6957,1.0941,1.4989 ; 1) \\
\quad(0.1483,0.1604,0.1917,0.2124 ; 1) \\
(0.986,0.986,0.986,0.986 ; 1) \\
\quad . .(0.4069,0.4702,0.6219,0.7206 ; 1)
\end{array}
$$

\section{$O$}

$(0.1561,0.1696,0.2049,0.2288 ; 1)$

$(0.986,0.986,0.986,0.986 ; 1)$

$(0.1659,0.1813,0.2228,0.2519 ; 1)$

$(0.6211,0.7826,1.3382,1.6279 ; 1)$

$(0.2096,0.2007,0.3229,0.3945 ; 1)$

$$
S-C
$$

$(0.286,0.3105,0.531,0.7495 ; 1)$

$(2.2574,2.7576,3.7526,4.2486 ; 1)$

$(0.1999,0.2049,0.2898,0.3418 ; 1)$

$(1.292,1.3768,1.9802,2.2883 ; 1)$

$(0.986,0.986,0.986,0.986 ; 1)$

\author{
(3.2557,3.7526,4.744,5.239;1) \\ (3.8601,4.3628,5.3626,5.8608;1) \\ $(0.986,0.986,0.986,0.986 ; 1)$ \\ $(4.5767,5.0722,6.062,6.5564 ; 1)$ \\ $(2.6085,3.0765,4.0013,4.4604 ; 1) \ldots$
}

Fig. 13. The aggregated fuzzy pairwise comparison matrix for criteria evaluation after conversion process

Step 5: Defuzzify the fuzzy numbers after transformed for znumbers.

Defuzzify trapezoidal fuzzy weights using intuitive vectorial centroid, equation (20) for $x$-axis. For the evaluation of criteria by DMs for this stage, the degree of confidence of the DMs' opinions are agreed as highest degree which is 1 . The pairwise comparison matrices of DMs' preferences are aggregated as shown example from one of the DM's evaluation.

$$
\begin{aligned}
& \tilde{A}=(5,5.5,6.5,7 ; 1) \\
& \widetilde{B}=(0.75,1,1,1 ; 1)
\end{aligned}
$$

The DM's knowledge can be expressed to z-number as

$$
Z=[(5,5.5,6.5,7 ; 1)(0.75,1,1,1 ; 1)]
$$

\begin{tabular}{|c|c|c|c|c|c|c|}
\hline & & $E S$ & $O$ & $P$ & $P E$ & $S-C$ \\
\hline \multirow{5}{*}{ Defuzzify = } & $E S$ & {$[0.986$} & 0.1884 & 4.2481 & 0.1770 & $0.4423^{-}$ \\
\hline & $O$ & 5.2387 & 0.986 & 4.8622 & 0.9262 & 3.2546 \\
\hline & $P$ & 0.2243 & 0.2036 & 0.986 & 0.1770 & 0.2526 \\
\hline & $P E$ & 5.3313 & 1.0747 & 5.567 & 0.986 & 1.7033 \\
\hline & $S-C$ & 2.1587 & 0.2708 & 3.5379 & 0.55 & 0.986 \\
\hline
\end{tabular}

At first, the reliability component should be converted into crisp using equation (7) for $x$-axis.

$$
\begin{aligned}
& \alpha=\frac{2(0.75+1)+7(1+1)}{18}=0.9722 \\
& Z^{\alpha}=[(5,5.5,6.5,7 ; 0.9722)]
\end{aligned}
$$

Add the weight of the reliability to the constraint. Convert the weighted z-number to regular fuzzy number according to the proposed approach.

$$
\begin{aligned}
& \tilde{Z}^{\prime}=(\sqrt{0.9722} \times 5, \sqrt{0.9722} \times 5.5, \sqrt{0.9722} \times 6.5, \sqrt{0.9722} \times 7 ; 1) \\
& \tilde{Z}^{\prime}=(4.93,5.4231,6.4091,6.9021 ; 1)
\end{aligned}
$$

Do the same computation for DMs' judgement for all criteria. Fig. 14 shows the defuzzification results of aggregated matrix comparison.

Fig. 14. Defuzzification results of aggregated matrix comparison

Step 5: Compute the criteria values as weights for alternatives' evaluation using consistent fuzzy preference relations.

The aggregated matrix comparison of each criterion is calculated in Fig. 15.

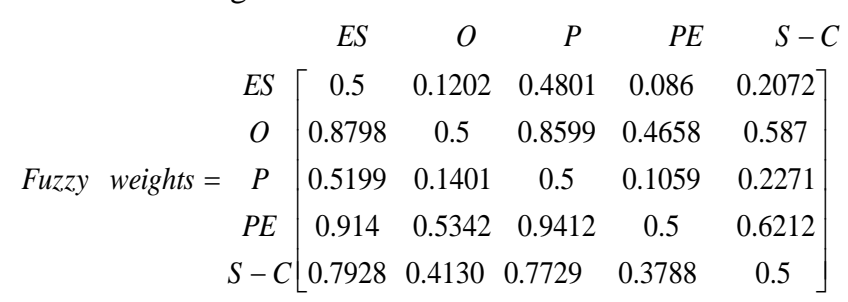

Fig. 15. The consistent fuzzy preference relations matrix for criteria 
By having five criteria, $n=5$ so only $(n-1)=5-1=4$ entry values $\left(p_{12}, p_{23}, p_{34}\right.$ and $\left.p_{45}\right)$ are required in constructing the consistent fuzzy preference relations matrix from Fig. 14 where:

$$
\begin{aligned}
& p_{12}=\frac{1}{2}\left(1+\log _{9} 0.1884\right)=0.1202 \\
& p_{23}=\frac{1}{2}\left(1+\log _{9} 4.8622\right)=0.8599 \\
& p_{34}=\frac{1}{2}\left(1+\log _{9} 0.1770\right)=0.1059 \\
& p_{45}=\frac{1}{2}\left(1+\log _{9} 1.7033\right)=0.6212
\end{aligned}
$$

The remains of the entries can be determined by utilizing Proposition 2 and 3 by presented as follows:

$$
\begin{aligned}
& p_{21}=1-p_{12}=1-0.1202=0.8798 \\
& p_{31}=\frac{3}{2}-p_{12}-p_{23}=\frac{3}{2}-0.1202-0.8599=0.5199 \\
& p_{51}=\frac{5-1+1}{2}-p_{12}-p_{23}-p_{34}-p_{45}=\frac{5}{2}-0.1202-0.8599 \\
& -0.1059-0.6212=0.7928
\end{aligned}
$$

Notes: Some of remains entries are not shown for calculation.

$$
\begin{aligned}
& \text { ES } \quad O \quad P \quad P E \quad S-C \text { Average Weights Rank }
\end{aligned}
$$

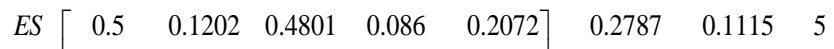

$$
\begin{aligned}
& \begin{array}{llllllll|lll}
O & 0.8798 & 0.5 & 0.8599 & 0.4658 & 0.587 & 0.6585 & 0.2634 & 2
\end{array} \\
& \begin{array}{l|lllll|lll}
P & 0.5199 & 0.1401 & 0.5 & 0.1059 & 0.2271 & 0.2986 & 0.1195 & 4
\end{array} \\
& \begin{array}{l|lllll|lll}
P E & 0.914 & 0.5342 & 0.9412 & 0.5 & 0.6212 & 0.6927 & 0.2771 & 1
\end{array}
\end{aligned}
$$

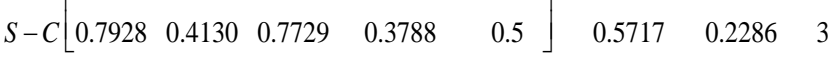

Fig. 16. The average and weights for criteria

Then, the average and weights of each criterion are illustrated in Fig. 16. Referring to Fig 16, 'past experience' criterion has highest weights value with $0.2771(27.71 \%)$. Followed by 'oration' 0.2634 (26.34\%), 'self-confidence' 0.2286 (22.86\%), 'personality' $0.1195(11.95 \%)$ and 'emotional steadiness' with $0.1115(11.15 \%)$. Which mean, based on decision makers evaluations, 'past experience, 'oration' and 'self-confidence' criteria play important aspects in recruiting new staff.

Referring to Table 5, the comparison weights of criteria of established and proposed models are presented. Z-AHP [8] and Z-TOPSIS [29] give same ranking results for criteria with $\mathrm{O}>\mathrm{PE}>\mathrm{S}-\mathrm{C}>\mathrm{ES}>\mathrm{P}$, but different with proposed model which the ranking results of criteria is $\mathrm{PE}>\mathrm{O}>\mathrm{S}-\mathrm{C}>\mathrm{P}>\mathrm{ES}$. Both $\mathrm{Z}$ AHP [8] and Z-TOPSIS [29] evaluate criteria simply by getting the aggregation results from several decision matrices The authors prefer to utilise consistent fuzzy preference relations technique order to avoid misleading solution in expressing the decision makers' opinions by means of preference relations.

\section{Phase 3: Ranking evaluation of alternatives using fuzzy TOPSIS}

The steps of fuzzy TOPSIS are illustrated as follows [12]:

Step 1: Determine the weights of evaluation criteria

The weights of evaluation criteria are employed from consistent fuzzy preference relations process before.

Step 2: Construct the fuzzy decision matrix and aggregate

\begin{tabular}{|c|c|c|c|c|}
\hline \multirow{2}{*}{ Criteria } & \multirow{2}{*}{$\begin{array}{l}\text { Alternatives/ } \\
\text { Candidates }\end{array}$} & \multicolumn{3}{|c|}{ Decision Maker } \\
\hline & & $D M 1$ & $D M 2$ & $D M 3$ \\
\hline \multirow[t]{4}{*}{ Emotional Steadiness } & $x I$ & $\mathrm{FH}(\mathrm{VH})$ & $\mathrm{H}(\mathrm{VH})$ & $\mathrm{VH}(\mathrm{H})$ \\
\hline & $x^{2}$ & $\mathrm{H}(\mathrm{H})$ & $\mathrm{H}(\mathrm{VH})$ & $\mathrm{FH}(\mathrm{VH})$ \\
\hline & $x 3$ & $\mathrm{VH}(\mathrm{VH})$ & $\mathrm{H}(\mathrm{VH})$ & $\mathrm{VH}(\mathrm{VH})$ \\
\hline & $x 4$ & $\mathrm{M}(\mathrm{VH})$ & $\mathrm{FH}(\mathrm{VH})$ & $\mathrm{M}(\mathrm{VH})$ \\
\hline \multirow[t]{4}{*}{ Oral } & $x I$ & $\mathrm{VH}(\mathrm{VH})$ & $\mathrm{H}(\mathrm{VH})$ & $\mathrm{VH}(\mathrm{VH})$ \\
\hline & $x^{2}$ & $\mathrm{H}(\mathrm{VH})$ & $\mathrm{H}(\mathrm{H})$ & $\mathrm{VH}(\mathrm{VH})$ \\
\hline & $x 3$ & $\mathrm{VH}(\mathrm{VH})$ & $\mathrm{VH}(\mathrm{VH})$ & $\mathrm{H}(\mathrm{VH})$ \\
\hline & $x 4$ & $\mathrm{FH}(\mathrm{H})$ & $\mathrm{M}(\mathrm{VH})$ & $\mathrm{FH}(\mathrm{VH})$ \\
\hline \multirow[t]{4}{*}{ Personality } & $x I$ & $\mathrm{VH}(\mathrm{VH})$ & $\mathrm{VH}(\mathrm{VH})$ & $\mathrm{VH}(\mathrm{VH})$ \\
\hline & $x^{2}$ & $\mathrm{H}(\mathrm{VH})$ & $\mathrm{H}(\mathrm{VH})$ & $\mathrm{VH}(\mathrm{VH})$ \\
\hline & $x 3$ & $\mathrm{VH}(\mathrm{VH})$ & $\mathrm{VH}(\mathrm{VH})$ & $\mathrm{VH}(\mathrm{VH})$ \\
\hline & $x 4$ & $\mathrm{H}(\mathrm{VH})$ & $\mathrm{H}(\mathrm{VH})$ & $\mathrm{H}(\mathrm{VH})$ \\
\hline \multirow[t]{4}{*}{ Past Experience } & $x I$ & $\mathrm{FL}(\mathrm{VH})$ & $\mathrm{L}(\mathrm{VH})$ & FL $(\mathrm{VH})$ \\
\hline & $x^{2}$ & $\mathrm{M}(\mathrm{VH})$ & $\mathrm{M}(\mathrm{H})$ & $\mathrm{M}(\mathrm{VH})$ \\
\hline & $x^{3}$ & $\mathrm{H}(\mathrm{H})$ & $\mathrm{M}(\mathrm{VH})$ & $\mathrm{H}(\mathrm{VH})$ \\
\hline & $x 4$ & $\mathrm{FL}(\mathrm{VH})$ & $\mathrm{FL}(\mathrm{VH})$ & FL (VH) \\
\hline \multirow[t]{4}{*}{ Self-Confidence } & $x I$ & $\mathrm{H}(\mathrm{VH})$ & $\mathrm{FH}(\mathrm{VH})$ & $\mathrm{FH}(\mathrm{VH})$ \\
\hline & $x^{2}$ & $\mathrm{VH}(\mathrm{H})$ & $\mathrm{H}(\mathrm{VH})$ & $\mathrm{H}(\mathrm{H})$ \\
\hline & $x 3$ & $\mathrm{VH}(\mathrm{VH})$ & $\mathrm{VH}(\mathrm{VH})$ & $\mathrm{VH}(\mathrm{VH})$ \\
\hline & $x 4$ & $\mathrm{M}(\mathrm{VH})$ & $\mathrm{FH}(\mathrm{VH})$ & $\mathrm{FH}(\mathrm{VH})$ \\
\hline
\end{tabular}
them.

The fuzzy decision matrix is constructed and the linguistic terms from Table 2 and Table 3 (reliability) are used to evaluate the alternatives with respect to criteria. The alternatives' evaluations are presented in Table 4, Fig. 17, 18 and 19 . Then, the aggregated result is computed and presented in Fig. 20.

Table 4. Evaluating linguistic terms of the alternatives with reliability components given by the decision makers with respect to different criteria

Table 5. Comparison of weights of criteria

\begin{tabular}{c|c|c|c|c|c|c}
\hline \multirow{2}{*}{ Z-numbers MCDM Model } & \multicolumn{5}{|c|}{ Criteria weight values } & \multirow{2}{*}{ Ranking Results } \\
\cline { 2 - 6 } & $(\boldsymbol{E S})$ & \multicolumn{1}{|c|}{$(\boldsymbol{O})$} & $(\boldsymbol{P})$ & $(\boldsymbol{P E})$ & \multicolumn{1}{c}{$(\boldsymbol{S}-\boldsymbol{C})$} & \\
\hline Z-AHP [8] & 0.0887 & 0.3661 & 0.045 & 0.3405 & 0.1602 & $\mathrm{O}>\mathrm{PE}>\mathrm{S}-\mathrm{C}>\mathrm{ES}>\mathrm{P}$ \\
Z-TOPSIS [29] & 0.0631 & 0.4044 & 0.009 & 0.3736 & 0.1499 & $\mathrm{O}>\mathrm{PE}>\mathrm{S}-\mathrm{C}>\mathrm{ES}>\mathrm{P}$ \\
Z-CFPR-TOPSIS (Proposed) & 0.1115 & 0.2634 & 0.1195 & 0.2771 & 0.2286 & PE $>\mathrm{O}>\mathrm{S}-\mathrm{C}>\mathrm{P}>\mathrm{ES}$ \\
\hline
\end{tabular}




\begin{tabular}{|c|c|c|c|c|c|}
\hline \multirow{5}{*}{$D M 1=$} & $E S$ & {$[(0.5719,0.6212,0.7888,0.8480 ; 1)$} & $(0.6235,0.6755,0.7967,0.84 ; 1)$ & $(0.917,0.9663,0.986,0.986 ; 1)$ & $(0.3155,0.4043,0.5719,0.6409 ; 1)$ \\
\hline & $O$ & $(0.917,0.9663,0.986,0.986 ; 1)$ & $(0.7099,0.7691,0.9071,0.9564 ; 1)$ & $(0.917,0.9663,0.986,0.986 ; 1)$ & $(0.5023,0.5456,0.6928,0.7448 ; 1)$ \\
\hline & $P$ & $(0.917,0.9663,0.986,0.986 ; 1)$ & $(0.7099,0.7691,0.9071,0.9564 ; 1)$ & $(0.917,0.9663,0.986,0.986 ; 1)$ & $(0.7099,0.7691,0.9071,0.9564 ; 1)$ \\
\hline & $P E$ & $(0.1676,0.2169,0.355,0.4141 ; 1)$ & $(0.3155,0.4043,0.5719,0.6409 ; 1)$ & $(0.6235,0.6755,0.7967,0.84 ; 1)$ & $(0.1676,0.2169,0.355,0.4141 ; 1)$ \\
\hline & $S-C$ & $(0.7099,0.7691,0.9071,0.9564 ; 1)$ & $(0.8054,0.8487,0.866,0.866 ; 1)$ & $(0.917,0.9663,0.986,0.986 ; 1)$ & $(0.3155,0.4043,0.5719,0.6409 ; 1)$ \\
\hline
\end{tabular}

Fig. 17. The fuzzy pairwise comparison matrix of DM1 for alternatives evaluation after conversion process

$x 1$

\begin{tabular}{|c|c|c|}
\hline \multirow{5}{*}{$D M 2=$} & $E S$ & $\Gamma(0.7099,0.7691,0.9071,0.9564 ; 1)$ \\
\hline & $O$ & $(0.7099,0.7691,0.9071,0.9564 ; 1)$ \\
\hline & $P$ & $(0.917,0.9663,0.986,0.986 ; 1)$ \\
\hline & $P E$ & $(0.0394,0.0986,0.1775,0.2268 ; 1)$ \\
\hline & $S$ & $(0.5719,0.6212,0.7888,0.848 ; 1)$ \\
\hline
\end{tabular}

$x 2$

$(0.7099,0.7691,0.9071,0.9564 ; 1)$ (0.6235,0.6755,0.7976,0.84;1)

$(0.7099,0.7691,0.9071,0.9564 ; 1)$

$(0.2771,0.3551,0.5023,0.5629 ; 1)$

$(0.7099,0.7691,0.9071,0.9564 ; 1)$ $x 3$

$(0.7099,0.7691,0.9071,0.9564 ; 1)$

$(0.917,0.9663,0.986,0.986 ; 1)$

$(0.917,0.9663,0.986,0.986 ; 1)$

$(0.3155,0.4043,0.5719,0.6409 ; 1)$

$(0.917,0.9663,0.986,0.986 ; 1)$ $x 4$

$(0.5719,0.6212,0.7888,0.848 ; 1)$ $(0.3155,0.4043,0.5719,0.6409 ; 1)$ $(0.7099,0.7691,0.9071,0.9564 ; 1)$

$(0.1676,0.2169,0.355,0.4141 ; 1)$

$(0.5719,0.6212,0.7888,0.848 ; 1)$

Fig. 18. The fuzzy pairwise comparison matrix of DM2 for alternatives evaluation after conversion process

$x 1$

\begin{tabular}{|c|c|c|}
\hline \multirow{5}{*}{$D M 3=$} & $E S$ & (0.8054,0.8487,0.866,0.866;1) \\
\hline & $O$ & $(0.917,0.9663,0.986,0.986 ; 1)$ \\
\hline & $P$ & $(0.917,0.9663,0.986,0.986 ; 1)$ \\
\hline & $P E$ & $(0.1676,0.2169,0.355,0.4141 ; 1)$ \\
\hline & $S-C$ & $(0.5719,0.6212,0.7888,0.848 ; 1)$ \\
\hline
\end{tabular}

$x 2$

$(0.5719,0.6212,0.7888,0.848 ; 1)$ $(0.917,0.9663,0.986,0.986 ; 1)$ $(0.917,0.9663,0.986,0.986 ; 1)$

$(0.3155,0.4043,0.5719,0.6409 ; 1)$ $(0.6235,0.6755,0.7967,0.840 ; 1)$ $x 3$

$(0.917,0.9663,0.986,0.986 ; 1)$ $(0.7099,0.7691,0.9071,0.9564 ; 1)$ $(0.917,0.9663,0.986,0.986 ; 1)$ $(0.7099,0.7691,0.9071,0.9564 ; 1)$ $(0.9170,0.9663,0.986,0.986 ; 1)$ $x 4$

$(0.3155,0.4043,0.5719,0.6409 ; 1)$ $(0.5719,0.6212,0.7888,0.848 ; 1)$ $(0.7099,0.7691,0.9071,0.9564 ; 1)$ $(0.1676,0.2169,0.355,0.4141 ; 1)$ $(0.5719,0.6212,0.7888,0.848 ; 1)$

Fig. 19. The fuzzy pairwise comparison matrix of DM3 for alternatives evaluation after conversion process

$x 1$

$x 2$ $x 4$

$E S$
$O$$\left[\begin{array}{ccccc}(0.6889,0.7401,0.8526,0.8889 ; 1) & (0.6326,0.6859,0.8292,0.8799 ; 1) & (0.8420,0.8955,0.9590,0.9761 ; 1) & (0.3847,0.4665,0.6366,0.7036 ; 1) \\ (0.8420,0.8955,0.9590,0.9761 ; 1) & (0.7404,0.7948,0.8932,0.9253 ; 1) & (0.8420,0.8955,0.9590,0.9761 ; 1) & (0.5188,0.5944,0.7449,0.8015 ; 1)\end{array}\right.$

$E S$
$O$$\left[\begin{array}{ccccc}(0.6889,0.7401,0.8526,0.8889 ; 1) & (0.6326,0.6859,0.8292,0.8799 ; 1) & (0.8420,0.8955,0.9590,0.9761 ; 1) & (0.3847,0.4665,0.6366,0.7036 ; 1) \\ (0.8420,0.8955,0.9590,0.9761 ; 1) & (0.7404,0.7948,0.8932,0.9253 ; 1) & (0.8420,0.8955,0.9590,0.9761 ; 1) & (0.5188,0.5944,0.7449,0.8015 ; 1)\end{array}\right]$

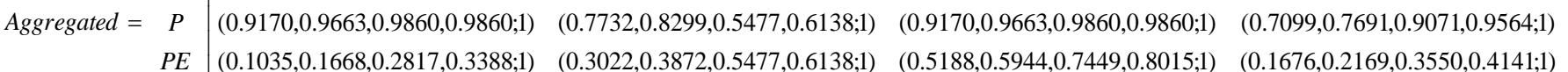

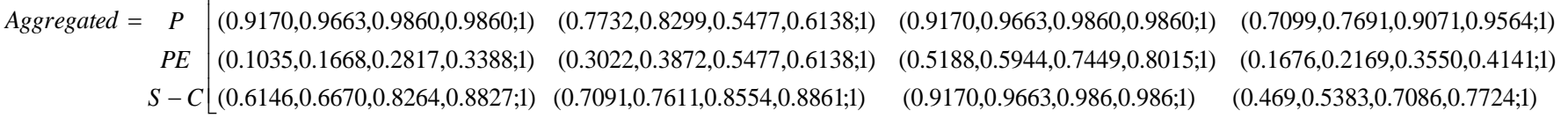
$P E$
$S-C$$\left(\begin{array}{lllll}(0.1035,0.1668,0.2817,0.3388 ; 1) & (0.3022,0.3872,0.5477,0.6138 ; 1) & (0.5188,0.5944,0.7449,0.8015 ; 1) & (0.1676,0.2169,0.3550,0.4141 ; 1) \\ (0.6146,0.6670,0.8264,0.8827 ; 1) & (0.7091,0.7611,0.8554,0.8861 ; 1) & (0.9170,0.9663,0.986,0.986 ; 1) & (0.469,0.5383,0.7086,0.7724 ; 1)\end{array}\right.$

Fig. 20. The aggregated fuzzy pairwise comparison matrix for alternatives evaluation after conversion process

Step 3: Fuzzy decision matrix is weighted and normalised.

The weights from consistent fuzzy preference relations are adopted here. The weighted and normalised fuzzy decision matrix are depicted in Fig. 21 and 22. The weighted fuzzy decision matrix is denoted by $\tilde{V}$ as depicted below with numerical example:

$$
\begin{aligned}
& \tilde{v}_{\text {Aggregated } x 1, E S}=(0.6889,0.7401,0.8526,0.8889 ; 1) \times 0.1115 \\
& \tilde{v}_{\text {Aggregated } x 1, E S}=(0.0768,0.0825,0.095,0.0099 ; 1)
\end{aligned}
$$

Convert each generalised trapezoidal fuzzy numbers into standardised generalised fuzzy numbers using normalisation process by [26] from equation (29).
Step 4: Defuzzify the standardised generalised fuzzy numbers. Defuzzify the standardised generalised trapezoidal fuzzy numbers using intuitive vectorial centroid method, then translate them into the index point proposed by [27], as depicted in Fig. 23 and 24. Use the new point of $y_{\tilde{A}_{i}^{*}}$ to compute fuzzy positive-ideal solution and fuzzy negative ideal solution. Thea average of translated defuzzified pairwise comparison matrix for alternatives solution is presented in Fig. 25 . $x 1$

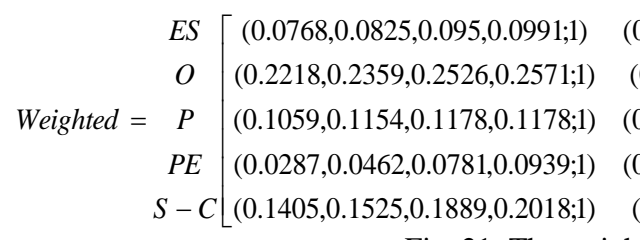

$x 2$ $\begin{array}{llll}(0.0705,0.0765,0.0924,0.0981 ; 1) & (0.0939,0.0998,0.1069,0.1088 ; 1) & (0.0429,0.052,0.071,0.0784 ; 1)\end{array}$ $\begin{array}{llll}(0.195,0.2093,0.2353,0.2437 ; 1) & (0.2218,0.2359,0.2526,0.2571 ; 1) & (0.1367,0.1484,0.1885,0.2026 ; 1)\end{array}$ $\begin{array}{cccc}(0.0924,0.0991,0.1114,0.1154 ; 1) & (0.1095,0.1154,0.1178,0.1178 ; 1) & (0.0848,0.0919,0.1084,0.1143 ; 1)\end{array}$ $\begin{array}{llll}(0.0837,0.1073,0.1517,0.1701 ; 1) & (0.1438,0.1647,0.2064,0.2221 ; 1) & (0.0464,0.0601,0.0984,0.1147 ; 1)\end{array}$ $(0.1621,0.174,0.1955,0.2026 ; 1) \quad(0.2096,0.2209,0.2254,0.2254 ; 1) \quad(0.1072,0.1231,0.162,0.1766 ; 1)$

Fig. 21. The weighted fuzzy pairwise comparison matrix for alternatives evaluation 


$E S$
$O$$\quad\left[\begin{array}{ccccc}(0.2107,0.2357,0.2905,0.3083 ; 1) & (0.1832,0.2092,0.2791,0.3039 ; 1) & (0.2854,0.3115,0.3425,0.3508 ; 1) & (0.0622,0.1021,0.1851,0.2178 ; 1) & 1 \\ \text { Normalised }= & P \\ P E & (8454,0.9071,0.9803,1 ; 1) & (0.7283,0.7910,0.9045,0.9415 ; 1) & (0.8454,0.9071,0.9803,1 ; 1) & (0.4727,0.5243,0.6996,0.7615 ; 1) \\ S-C & (0,0.0768,0.3798,0.3901,0.3901 ; 1) & (0.2788,0.3085,0.3622,0.3797 ; 1) & (0.354,0.3798,0.3901,0.3901 ; 1) & (0.2457,0.2767,0.3488,0.3746 ; 1) \\ (0.4896,0.542,0.7015,0.7578 ; 1) & (0.5841,0.6362,0.7305,0.76131) & (0.7922,0.8415,0.8612,0.8612 ; 1) & (0.3439,0.4132,0.5836,0.6475 ; 1)\end{array}\right]$

Fig. 22. The normalised fuzzy pairwise comparison matrix for alternatives evaluation

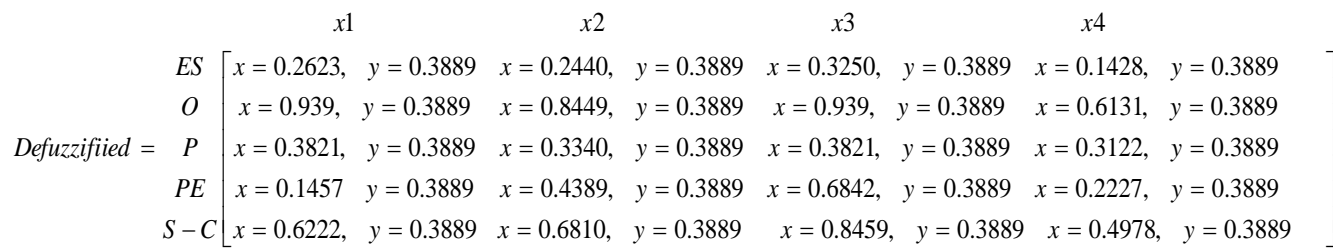

Fig. 23. The defuzzified pairwise comparison matrix for alternatives evaluation

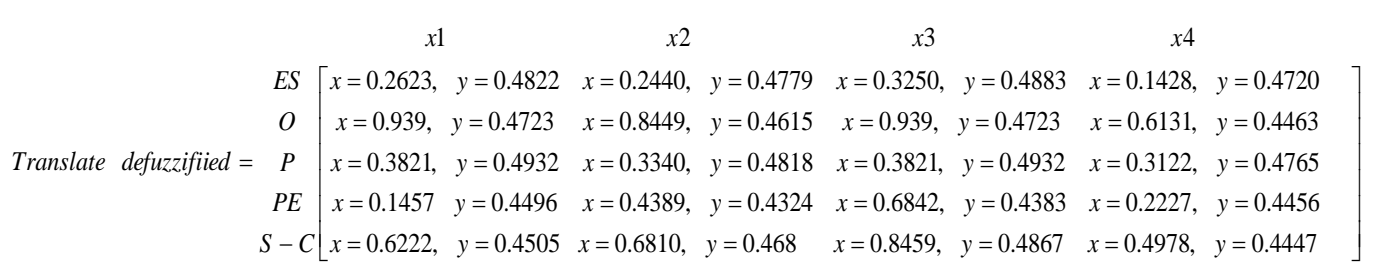

Fig. 24. The defuzzified pairwise comparison matrix for alternatives evaluation

$$
x 1 \quad x 2 \quad x 3 \quad x 4
$$

Average Translate defuzzifiied $=[x=0.4703, y=0.4695 \quad x=0.5086, y=0.4643 \quad x=0.6352 \quad y=0.4758 \quad x=0.3577, \quad y=0.457 \quad]$

Fig. 25. The average translate defuzzified pairwise comparison matrix for alternatives evaluation

Step 5: Determine the fuzzy positive-ideal solution (FPIS) and fuzzy negative-ideal solution (FNIS).

Referring to normalise trapezoidal fuzzy weights, the FPIS, $A^{+}$represents the compromise solution while FNIS, $A^{-}$represents the worst possible solution. The range belong to the closed interval [0,1]. The FPIS $A^{+}$(aspiration levels) and FNIS $A^{-}$(worst levels) as following below.

$$
A^{+}=[1,1,1,1 ; 1] \quad A^{-}=[-1,-1,-1,-1 ; 1]
$$

The FPIS, $A^{+}$and FNIS, $A^{-}$can be obtained by centroid method for $\left(x_{A^{+}}, y_{A^{+}}\right)$and $\left(x_{A^{-}}, y_{A^{-}}\right)$.

Step 6: Calculate the distance of each alternative from FPIS and FNIS.

The distance $\tilde{d}_{i}^{+}$and $\tilde{d}_{i}^{-}$of each alternative from formulation $A^{+}$and $A^{-}$can be calculated by the area of compensation method.

$$
\begin{aligned}
& \bar{d}_{i}^{+}\left(\tilde{v}_{i j}, \tilde{v}_{j}^{+}\right)=\sqrt{\left(x_{\tilde{A}_{i}^{*}}-x_{A^{+}}\right)^{2}+\left(y_{\tilde{A}_{i}^{*}}-y_{A^{+}}\right)^{2}} \\
& \bar{d}_{i}^{-}\left(\tilde{v}_{i j}, \tilde{v}_{j}^{-}\right)=\sqrt{\left(x_{\tilde{A}_{i}^{*}}-x_{A^{-}}\right)^{2}+\left(y_{\tilde{A}_{i}^{*}}-y_{A^{-}}\right)^{2}}
\end{aligned}
$$

The numerical calculation is shown as follows.

$$
\begin{aligned}
& \bar{d}_{\text {candidatd }}^{+}=\sqrt{(0.4703-1)^{2}+(0.4695-0.5)^{2}} \\
& \bar{d}_{\text {candidatd }}^{+}=0.5306 \\
& \bar{d}_{\text {candidatd }}^{-}=\sqrt{(0.4603-(-1))^{2}+(0.4695-0.5)^{2}} \\
& \bar{d}_{\text {candidad }}^{-}=1.4706
\end{aligned}
$$

Step 7: Find the closeness coefficient, $C C_{i}$ and improve alternatives for achieving aspiration levels in each criteria. Notice that the highest $C C_{i}$ value is used to determine the rank.

$$
\overline{C C}_{i}=\frac{\bar{d}_{i}^{-}}{\bar{d}_{i}^{+}+\bar{d}_{i}^{-}}=1-\frac{\bar{d}_{i}^{+}}{\bar{d}_{i}^{+}+\bar{d}_{i}^{-}}
$$

Hence, the numerical calculation is shown as

$$
\begin{aligned}
& \overline{C C}_{\text {candidatad }}=\frac{1.4706}{1.4706+0.5306} \\
& \overline{C C}_{\text {candidara }}=0.7348
\end{aligned}
$$

Table 6. Closeness coefficients computation.

\begin{tabular}{ll}
\hline Alternative & Closeness Coefficient, $\boldsymbol{C} \boldsymbol{C}_{\boldsymbol{i}}$ \\
\hline Candidate 1 & $0.7348($ Rank 3$)$ \\
Candidate 2 & $0.7538($ Rank 2$)$ \\
Candidate 3 & 0.8173 (Rank 1) \\
Candidate 4 & 0.6785 (Rank 4) \\
\hline
\end{tabular}


The closeness coefficient, $C C_{i}$ values present that the candidate 3 achieves the highest rank with 0.8173 followed by candidate 2 with 0.7538 , candidate 1 with 0.7348 and candidate 4 with 0.6785 for the last ranked. The results reveal that the candidate 3 is most suitable for this recruitment because has highest $C C_{i}$ value.

Table 7 depicts the ranking results of all the established and proposed models for alternatives. All models present same ranking for alternatives/ candidates with Alt3>Alt2>Alt1>Alt4. This is showed that the proposed model is consistent with established models for z-numbers in terms of ranking results.

\section{Phase 3: Ranking evaluation of alternatives using fuzzy TOPSIS}

In sensitivity analysis evaluation, the focus is to test the effect of the criteria weights on the ranking of the results. The tests are process by increasing each original criteria weight by $50 \%$, $100 \%$ and $150 \%$. While one criterion is increased, the values of the remaining criteria are decreased by certain amount, such that the total amount of criteria are equal to one. Referring to Table 8, the proposed Z-CFPR-TOPSIS is quite robust and stable, since changes in the criteria weights significantly affect for several cases in the final ranking order of the alternatives candidates. As related before, the consistency of correct ranking order based on original rank presents $86.67 \%$ level of consistency. Even the ranking values are changed, but the ranking order are significantly consistent with the original ranking. However, when criterion 'Oration' are increased by $100 \%$ and $150 \%$, the ranking order are changed to Alt $3>$ Alt $1>$ Alt2 $>$ Alt 4 both of them. In the context of sensitivity analysis evaluation, it presents that the proposed hybrid fuzzy MCDM model for z-numbers is consistent even the weights of criteria are changed.

Table 9 summarises the sensitivity analysis results for all three comparative studies in this research work. Representing both established models (Z-AHP and Z-TOPSIS) achieve $66.67 \%$ of level of consistency while the proposed Z-CFPR-TOPSIS achieves $86.67 \%$. This is depicted that the proposed Z-CFPRTOPSIS model is more robust and reliable than Z-AHP [8] and Z-TOPSIS [29] to deal with uncertain environment in studying knowledge of human being. From the consistency results, the proposed Z-CFPR-TOPSIS model is recommended to deal with bigger case study in real world phenomena in order to solve human based decision making problems under fuzzy environment.

Table 7. Ranking results of alternatives for hybrid fuzzy MCDM models

\begin{tabular}{|c|c|c|c|c|c|}
\hline \multirow{2}{*}{ Z-numbers MCDM Model } & \multicolumn{4}{|c|}{ Alternative ranking values } & \multirow{2}{*}{ Ranking Results } \\
\hline & $($ Alt1) & (Alt2) & (Alt3) & (Alt4) & \\
\hline Z-AHP [8] & 0.2321 & 0.2584 & 0.3016 & 0.2079 & Alt3>Alt2>Alt1>Alt4 \\
\hline Z-TOPSIS [29] & 0.5503 & 0.5562 & 0.5678 & 0.5404 & Alt $3>$ Alt $2>$ Alt $1>$ Alt 4 \\
\hline Z-CFPR-TOPSIS (Proposed) & 0.7348 & 0.7538 & 0.8173 & 0.6785 & Alt $3>$ Alt $2>$ Alt $1>$ Alt 4 \\
\hline
\end{tabular}

Table 8. Sensitivity analysis results of proposed hybrid fuzzy MCDM model for z-numbers

\begin{tabular}{|c|c|c|c|c|c|c|}
\hline $\begin{array}{l}\text { Changes of } \\
\text { criteria (\%) }\end{array}$ & Alt1 & Alt2 & Alt3 & Alt4 & Ranking results & $\begin{array}{c}\text { Consistency } \\
\text { based on } \\
\text { original result }\end{array}$ \\
\hline ES' (50\%) & 0.7580 & 0.7759 & 0.8442 & 0.6945 & Alt3>Alt2>Alt1>Alt4 & Consistent \\
\hline ES' (100\%) & 0.7845 & 0.8010 & 0.8750 & 0.7127 & Alt3>Alt2>Alt1>Alt4 & Consistent \\
\hline ES' (150\%) & 0.7352 & 0.7465 & 0.8064 & 0.6746 & Alt3>Alt2>Alt1>Alt4 & Consistent \\
\hline $\mathrm{O}^{\prime}(50 \%)$ & 0.6673 & 0.6732 & 0.7101 & 0.6242 & Alt3>Alt2>Alt1>Alt4 & Consistent \\
\hline $\mathrm{O}^{\prime}(100 \%)$ & 0.6362 & 0.6359 & 0.6606 & 0.5991 & Alt3>Alt1>Alt2>Alt4 & Inconsistent \\
\hline $\mathrm{O}^{\prime}(150 \%)$ & 0.6182 & 0.6145 & 0.6321 & 0.5847 & Alt3>Alt1>Alt2>Alt4 & Inconsistent \\
\hline $\mathbf{P}^{\prime}(50 \%)$ & 0.7657 & 0.7817 & 0.8481 & 0.7050 & Alt3>Alt2>Alt1>Alt4 & Consistent \\
\hline$P^{\prime}(100 \%)$ & 0.7823 & 0.7941 & 0.8595 & 0.7208 & Alt3>Alt2>Alt1>Alt4 & Consistent \\
\hline$P^{\prime}(150 \%)$ & 0.7301 & 0.7359 & 0.7853 & 0.6823 & Alt3>Alt2>Alt1>Alt4 & Consistent \\
\hline $\mathrm{PE}^{\prime}(50 \%)$ & 0.6405 & 0.6678 & 0.7200 & 0.6097 & Alt3>Alt2>Alt1>Alt4 & Consistent \\
\hline PE' $(100 \%)^{\prime}$ & 0.5893 & 0.6179 & 0.6578 & 0.5761 & Alt3>Alt2>Alt1>Alt4 & Consistent \\
\hline PE' $(150 \%)^{\prime}$ & 0.5608 & 0.5901 & 0.6233 & 0.5574 & Alt3>Alt2>Alt1>Alt4 & Consistent \\
\hline S-C' $(50 \%)$ & 0.6810 & 0.6957 & 0.7428 & 0.6402 & Alt3>Alt2>Alt1>Alt4 & Consistent \\
\hline S-C' $(100 \%)$ & 0.6391 & 0.6503 & 0.6853 & 0.6096 & Alt3>Alt2>Alt1>Alt4 & Consistent \\
\hline S-C' $(150 \%)$ & 0.6151 & 0.6243 & 0.6524 & 0.5920 & Alt3>Alt2>Alt1>Alt4 & Consistent \\
\hline \multicolumn{6}{|c|}{ Level of consistency } & $86.67 \%$ \\
\hline
\end{tabular}


Table 9. Ranking results of alternatives

\begin{tabular}{c|c}
\hline Z-numbers MCDM Model & Level of Consistency \\
\hline Z-AHP [8] & $66.67 \%$ \\
Z-TOPSIS [29] & $66.67 \%$ \\
Z-CFPR-TOPSIS (Proposed) & $86.67 \%$ \\
\hline
\end{tabular}

\section{CONCLUSION}

This study has brought out the idea and concept regarding the hybrid fuzzy MCDM model that consist of consistent preference relations and fuzzy TOPSIS (Z-CFPR-TOPSIS) using intuitive vectorial centroid defuzzification method to deal with z-numbers. In dealing with the uncertainty and complexity in the information, the reliability of information must be taken into consideration efficiently. Z-number is a new notion that proposed by Zadeh has more capability in describing the uncertain and complex knowledge. The consideration of z-numbers in the research work provides

The development of extension of intuitive vectorial centroid provides an efficient computational defuzzification procedures for uncertain environment. It presents in simple formulae that based on the perspective of analytic geometric principles. In developing an intuitionistic defuzzification, a novel manner of computing intuitive vectorial centroid method has capability in dealing with all possible cases of fuzzy numbers. The novel Z-CFPR-TOPSIS model is developed by improvising several steps in computing the consistent fuzzy

\section{REFERENCES}

[1] A. Mardani, A. Jusoh, and E. K. Zavadskas, "Fuzzy multiple criteria decision-making techniques and applications - Two decades review from 1994 to 2014," Expert Syst. Appl., vol. 42, no. 8, pp. 41264148, Jan. 2015.

[2] X. Zhi-quan, "Application of Z-numbers in Multi-criteria Decision Making," in International Conference on Informantive and Cybernatics for Computational Social Systems (ICCSS), 2014, pp. 91-95.

[3] T. C. Wang and Y. H. Chen, "A New Method on Decision-Making Using Fuzzy Linguistic Assessment Variables and Fuzzy Preference Relations," Inf. Sci. (Ny)., vol. 178, no. 19, pp. 3755-3765, 2008

[4] L. A. Zadeh, "Fuzzy Sets-Information and Control-1965.pdf." Information and Controls, pp. 338-353, 1965.

[5] H. Deng, "Comparing and ranking fuzzy numbers using idea solutions," Appl. Math. Model., vol. 38, no. 5-6, pp. 1638-1646, Mar. 2014.

[6] L. A. Zadeh, "A Note on Z-numbers," Inf. Sci. (Ny)., vol. 181, no. 14, pp. 2923-2932, Jul. 2011.

[7] B. Kang, D. Wei, Y. Li, and Y. Deng, "A Method of Converting Z number to Classical Fuzzy Number," J. Inf. Comput. Sci., vol. 9, no. 3, pp. 703-709, 2012.

[8] A. Azadeh, M. Saberi, N. Z. Atashbar, E. Chang, and P. Pazhoheshfar, "Z-AHP: A Z-number extension of fuzzy analytical hierarchy process," 2013 7th IEEE Int. Conf. Digit. Ecosyst. Technol., pp. 141-147, 2013.

[9] D. P. Filev and R. R. Yager, "A generalized defuzzification method via bad distribution,” Int. J. Intell. Syst., vol. 6, pp. 687-697, 1991.

[10] K. M. N. Ku Khalif and A. Gegov, "Generalised Fuzzy Bayesian Network with Adaptive Vectorial Centroid," in 16th world congress of the international fuzzy systems association (IFSA) and the 9th preference relations and fuzzy TOPSIS to make sure both techniques are perfectly integrated. This proposed model capable to interact or cooperate with unlimited criteria in dealing with real world decision making problems.

The proposed Z-CFPR-TOPSIS model provides better selection in human based decision making problems where at the same capable to deal with uncertainty in human judgement. Due to access information and availability of the incomplete and uncertain data, it is hard to make right decision. In this sense, it is important to improvise the techniques or models form the classical one, adding intuitive reasoning and human subjectivity. As consequence, the proposed model is developed to design the robust and reliable methodology in order to give the most promising alternatives with respect to the resources. Therefore, this methodology can be further proceeded in order to make some contributions by considering complicated case studies drawn for diverse fields crossing human based decision making problems.

conference of the European society for fuzzy logic and technology (EUSFLAT), 2015, pp. 757-764.

[11] M. Velasquez and P. T. Hester, "An Analysis of Multi-Criteria Decision Making Methods,” Int. J. Oper. Res., vol. 10, no. 2, pp 56-66, 2013.

[12] C.-C. Sun, "A performance evaluation model by integrating fuzzy AHP and fuzzy TOPSIS methods," Expert Syst. Appl., vol. 37, no. 12, pp. 7745-7754, 2010

[13] Y. Shi, G. Kou, Y. Li, G. Wang, Y. Peng, and Y. Shi, "FMCDM: A fuzzy multi-criteria decision-making hybrid approach to evaluate the damage level of typhoon: Integration of fuzzy AHP and fuzzy TOPSIS," Inf. Sci. Interact. Sci. (ICIS), 2010 3rd Int. Conf., pp. 666-671, 2010.

[14] S. H. Zolfani, M. H. Esfahani, M. Bitarafan, E. K. Zavadskas, and S. L. Arefi, "Developing A New Hybrid MCDM Method for Selection of The Optimal Alternative of Mechanical Longitudinal Ventilation of Tunnel Pollutants During Automobile Accidents," Transport, vol. 28, no. 1, pp. 89-96, 2013.

[15] S. Vinodh, M. Prasanna, and N. Hari Prakash, "Integrated Fuzzy AHP-TOPSIS for selecting the best plastic recycling method: A case study," Appl. Math. Model., vol. 38, no. 19-20, pp. 4662-4672, Oct. 2014.

[16] E. Herrera-Viedma, F. Herrera, F. Chiclana, and M. Luque, "Some issues on consistency of fuzzy preference relations," Eur. J. Oper. Res., vol. 154, no. 1, pp. 98-109, 2004.

[17] T.-C. Wang and Y.-H. Chen, "Consistent Fuzzy Linguistic Preference Relations for Computer Integrated Manufactory Systems Selection," Proc. 9th Jt. Conf. Inf. Sci., pp. 2-5, 2006.

[18] S. H. Zanakis, A. Solomon, N. Wishart, and S. Dublish, "Multiattribute decision making: A simulation comparison of select methods," Eur. J. Oper. Res., vol. 107, pp. 507-529, 1998

[19] C.-L. Hwang and K. Yoon, Multiple Attribute Decision Making. New York: Springer, 1981. 
[20] A. Amini and A. Alinezhad, "Sensitivity Analysis of TOPSIS Technique: The Results of Change in the Weight of One Attribute on the Final Ranking of Alternatives," J. Optim. Ind. Eng., vol. 7, no. 2011, pp. 23-28, 2011.

[21] A. Bahremand and F. Smedt, "Distributed hydrological modeling and sensitivity analysis in Torysa Watershed, Slovakia," Water Resour. Manag., vol. 22, no. 3, pp. 393-408, 2008.

[22] D. J. Pannell, "Sensitivity Analysis of Normative Economic Models:Theoretical Framework and Practical Stratagies," J. Agric. Econ., vol. 16, pp. 139-152, 1997.

[23] C.-H. Cheng, "A new approach for ranking fuzzy numbers by distance method," Fuzzy Sets Syst., vol. 95, no. 3, pp. 307-317, May 1998.

[24] N. H. Kamis, K. Abdullah, H. Mohamed, S. Sudin, and W. Z. A. W. Ishak, "Decision making models based on consistent fuzzy preference relations with different defuzzification methods," 2011 IEEE Colloq. Humanit. Sci. Eng. CHUSER 2011, no. Chuser, pp. 845-850, 2011.

[25] T. C. Wang and Y. H. Chen, "Applying consistent fuzzy preference relations to partnership selection," Omega, vol. 35 , no. 4, pp. 384-
388, 2007.

[26] X. Zuo, L. Wang, and Y. Yue, "A New Similarity Measure of Generalized Trapezoidal Fuzzy Numbers and Its Application on Rotor Fault Diagnosis," Math. Probl. Eng., vol. 2013, pp. 1-10, 2013.

[27] D. Yong and L. Qi, “A TOPSIS-based centroid-index ranking method of fuzzy numbers and its application in decision-making," Int. J. Cybern. Syst., vol. 36, no. 6, pp. 581-595, 2005.

[28] C.-T. Chen, "Extensions of the TOPSIS for group decision-making under fuzzy environment," Fuzzy Sets Syst., vol. 114, no. 1, pp. 1-9, Aug. 2000.

[29] R. A. Krohling and E. Santo, "TODIM and TOPSIS with Znumbers,". CoRR abs/1609.05705, 2016.

[30] G. Zheng, N. Zhu, Z. Tian, Y. Chen, and B. Sun, “Application of a trapezoidal fuzzy AHP method for work safety evaluation and early warning rating of hot and humid environments," Saf. Sci., vol. 50, no. 2, pp. 228-239, Feb. 2012.

[31] B. Kang, D. Wei, Y. Li, and Y. Deng, "Decision Making Using Znumbers under Uncertain Environment," J. Comput. Inf. Syst., vol. 8, no. 7, pp. 2807-2814, 2012. 